\title{
Synthesis and antibacterial activity of novel lincomycin derivatives. II. Exploring (7S)-7-(5-aryl-1,3,4-thiadiazol-2-yl-thio)-7- deoxylincomycin derivatives
}

\author{
Ko Kumura, Yoshinari Wakiyama, Kazutaka Ueda, Eijiro Umemura, Takashi Watanabe, Megumi Kumura, \\ Takuji Yoshida and Keiichi Ajito
}

The synthesis and antibacterial activity of (7S)-7-(5-aryl-1,3,4-thiadiazol-2-yl-thio)-7-deoxylincomycin derivatives are described. These derivatives were mainly prepared by the Mitsunobu reaction of 2,3,4-tris-O-(trimethylsilyl)lincomycin and the corresponding thiols. Exploring structure-activity relationships of the substituent at the 5 position of a thiadiazole ring revealed that compounds with the ortho substituted phenyl group showed improved antibacterial activities against Streptococcus pneumoniae and Streptococcus pyogenes with erm gene compared with the reported compound (1) that had an unsubstituted benzene ring.

The Journal of Antibiotics (2017) 70, 655-663; doi:10.1038/ja.2016.139; published online 7 December 2016

\section{INTRODUCTION}

Lincomycin ${ }^{1}$ is a secondary metabolite of Streptomyces lincolnensis and active mainly against Gram positive bacteria. Clindamycin ${ }^{2}$ (CLDM) derived from lincomycin is a useful semisynthetic antibiotic that is most widely used in the lincosamide class (Figure 1). Lincosamide antibiotics are protein synthesis inhibitors ${ }^{3}$ that act on $50 \mathrm{~S}$ ribosome in a similar way to macrolide antibiotics such as clarithromycin. ${ }^{4}$ However, CLDM shows almost no antibacterial activity against resistant pathogens such as Streptococcus pneumoniae and Streptococcus pyogenes with erm gene as shown in Table 1. Moreover, major macrolides, clarithromycin and azithromycin, ${ }^{5}$ are also not active against those pathogens with erm gene. Erm methyltransferases methylate A2058Ec of rRNA and diminish the affinity of clinically important macrolides, lincosamides and streptogramin $\mathrm{B}^{3}$, and this mode of resistance is referred to as MLS resistance. ${ }^{6}$ Increased emergence of resistant bacteria has been causing serious problems at clinical sites. ${ }^{7}$ CLDM is attractive because of its safety and effectiveness against resistant pathogens with efflux pump. It is known that the antibacterial activities of macrolide antibiotics are influenced by efflux pumps of resistant S. pneumoniae and S. pyogenes with mef gene (Figure 1; Table 1). Furthermore, CLDM can be administered as oral and injectable agents. As a rare case, moreover, it has been reported that CLDM is effective for invasive group A streptococcal infections caused by S. pyogenes. ${ }^{8}$ According to these reasons, we selected lincosamide (not macrolide) as a starting material for medicinal chemistry. In order to generate a novel chemotherapeutic agent that is effective against resistant $S$. pneumoniae and $S$. pyogenes with erm and mef genes, we started chemical modification of lincomycin and clarified that (7S)-7-arylthio-7-deoxylincomycin derivatives ${ }^{9-11}$ and (7S)-7-(azetidin-3-yl-thio)-7-deoxylincomycin derivatives ${ }^{12}$ exhibited moderate to strong antibacterial activities against $S$. pneumoniae and $S$. pyogenes with erm gene. In this article, we report optimization of previously reported (7S)-7-deoxy-7-(5-phenyl-1,3,4-thiadiazol-2-yl-thio)lincomycin (1). On the other hand, telithromycin ${ }^{13}$ is effective enough against $S$. pneumoniae with erm gene, but it has been reported to have potential to cause side effects in clinical use. ${ }^{7}$ Novel azalides ${ }^{14}$ were generated starting from 16-membered macrolides, and several optimized 16-membered azalides ${ }^{15}$ are effective against resistant $S$. pneumoniae and $S$. pyogenes with erm gene. These analogs, however, are still under research process and have not been developed yet. Currently available oral drugs are not effective enough against resistant bacteria with erm and mef genes causing respiratory infections and have some problems in safety or taste in clinical site.

\section{Chemistry}

Schemes 1 and 2 show the synthetic routes for novel (7S)-7(5-aryl-1,3,4-thiadiazol-2-yl-thio)-7-deoxylincomycin derivatives. We utilized reported 2, 3, 4-tris-O-(trimethylsilyl)lincomycin $(2)^{16}$ as a substrate for the Mitsunobu reaction with various thiols as we reported earlier. ${ }^{10}$ After the Mitsunobu reaction, trimethylsilyl groups were removed by acid treatment to give 3-22 (Scheme 1). Although 


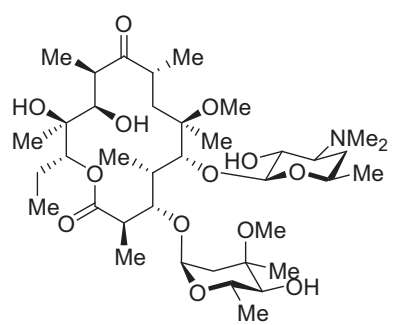

Clarithromycin (CAM)

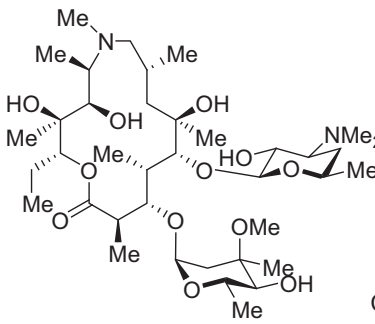

Azithromycin (AZM)<smiles>[R]C(C)=C(NC(=O)C1C[C@@H](CCC)CN1)[C@H]1O[C@H](C)[C@H](O)[C@H](O)[C@H]1O</smiles>

Lincomycin (LCM): $\mathrm{R}=-\mathrm{OH}$

Clindamycin (CLDM): $\mathrm{R}=\cdots \cdot \mathrm{Cl}$

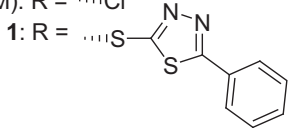

Figure 1 Structures of clinically important macrolides, lincomycin, clindamycin and compound 1.

Table 1 Antibacterial activities of CAM, AZM, LCM, CLDM and compound $1(\mathrm{MIC} ; \mu \mathrm{g} \mathrm{ml}-1)^{\mathrm{a}}$

\begin{tabular}{|c|c|c|c|c|c|c|c|}
\hline No. & Test organism ${ }^{b}$ & Characteristics & $C A M$ & $A Z M$ & LCM & CLDM & 1 \\
\hline 1 & Streptococcus pneumoniae DP1 type I & Susceptible & 0.03 & 0.06 & 1 & 0.13 & 0.13 \\
\hline 2 & S. pneumoniae \#2 & Susceptible & 0.03 & 0.03 & 1 & 0.13 & 0.06 \\
\hline 3 & S. pneumoniae \#3 & Susceptible & 0.015 & 0.03 & 0.25 & 0.13 & 0.06 \\
\hline 4 & S. pneumoniae \#4 & ermB methylase (c) & $>128$ & $>128$ & $>128$ & $>128$ & 64 \\
\hline 5 & S. pneumoniae \#5 & ermB methylase (c) & $>128$ & $>128$ & $>128$ & $>128$ & 32 \\
\hline 6 & S. pneumoniae \#6 & ermB methylase (c)+mefE & $>128$ & $>128$ & $>128$ & $>128$ & 128 \\
\hline 7 & S. pneumoniae \#7 & ermB methylase (i) & $>128$ & $>128$ & 128 & $>128$ & 16 \\
\hline 8 & S. pneumoniae \#8 & ermB methylase (i) & $>128$ & $>128$ & 128 & $>128$ & 16 \\
\hline 9 & S. pneumoniae \#9 & mefE efflux & 0.5 & 0.5 & 1 & 0.13 & 0.06 \\
\hline 10 & S. pneumoniae \#10 & mefE efflux & 0.5 & 0.5 & 1 & 0.13 & 0.06 \\
\hline 11 & Streptococcus pyogenes Cook & Susceptible & 0.015 & 0.06 & 0.13 & 0.13 & 0.06 \\
\hline 12 & S. pyogenes \#2 & ermB methylase (c) & $>128$ & $>128$ & $>128$ & $>128$ & 4 \\
\hline 13 & S. pyogenes \#3 & mefE efflux & 8 & 8 & 0.25 & 0.13 & 0.13 \\
\hline 14 & Haemophilus influenzae \#1 & Susceptible & 2 & 0.25 & 8 & 8 & 16 \\
\hline 15 & H. influenzae \#2 & Susceptible & 4 & 1 & 16 & 8 & 16 \\
\hline 16 & H. influenzae \#3 & Susceptible & 8 & 2 & 16 & 32 & 64 \\
\hline
\end{tabular}

Abbreviations: AZM, azithromycin; c, constitutive; CAM, clarithromycin; CLDM, clindamycin; i, inducible; LCM, lincomycin; MIC, minimum inhibitory concentration.

${ }^{a}$ Gray shading strains are target strains.

${ }^{\mathrm{b}}$ All strains except standard organisms were clinically isolated.

Me _ "

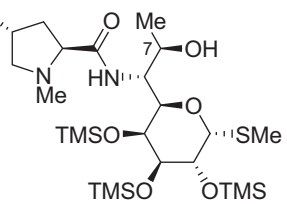

2

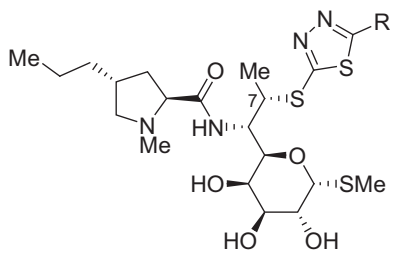

3-22<smiles>[R]=[V]Cc1ccc2ccccc2c1</smiles><smiles>[R][V]c1ccccn1</smiles><smiles>[R][I-]c1cccnc1</smiles><smiles>[R][I-]I(C)c1ccncc1</smiles><smiles>[R][V]c1cccs1</smiles>

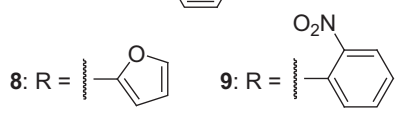<smiles>[R][V](C)(C)c1cccc([N+](=O)[O-])c1</smiles>
11: $\mathrm{R}=$<smiles>[R][I-]c1ccc([N+](=O)[O-])cc1</smiles><smiles>[R][I-]c1cnn(C)c1[N+](=O)[O-]</smiles>

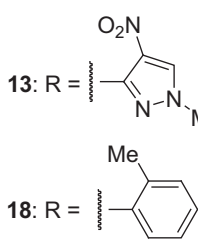
14<smiles>Cn1ncc(I)c1N</smiles><smiles>Nc1nccnc1I</smiles><smiles>[R]C(I)I</smiles>

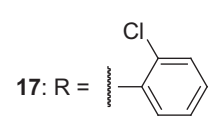<smiles>[R2]#Cc1ccccc1C#N</smiles>

Scheme 1 Synthesis of (7S)-7-(5-aryl-1,3,4-thiadiazol-2-yl-thio)-7-deoxylincomycin derivatives. Reagents: (a) ArSH, diethyl azodicarboxylate (DEAD), PPh 3 and tetrahydrofuran; (b) $1 \mathrm{~N} \mathrm{HCl}$ and $\mathrm{MeOH}$. 


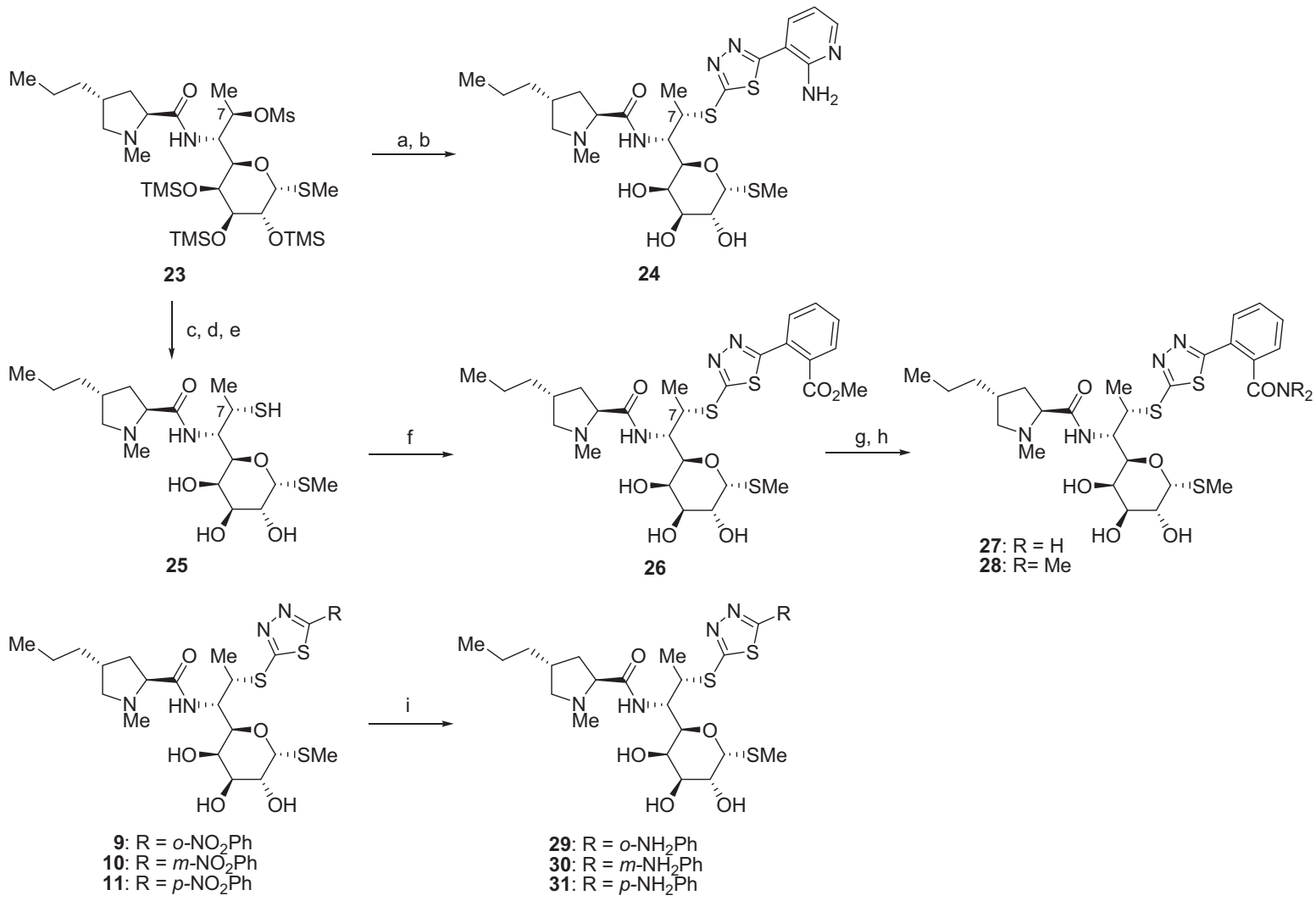

Scheme 2 Synthesis of (7S)-7-(5-aryl-1,3,4-thiadiazol-2-yl-thio)-7-deoxylincomycin derivatives. Reagents: (a) 5-(2-aminopyridin-3-yl)-1,3,4-thiadiazole-2-thiol, $\mathrm{K}_{2} \mathrm{CO}_{3}$ and DMF; (b) $1 \mathrm{~N} \mathrm{HCl}$ and $\mathrm{MeOH}$; (c) $\mathrm{KSAc}$ and DMF; (d) $2 \mathrm{~N} \mathrm{HCl}$ and $\mathrm{MeOH}$; (e) $\mathrm{NaOMe}$ and MeOH; (f) methyl 2-(5-chloro-1,3,4-thiadiazol-2-yl) benzoate, NaHMDS and DMF; (g) $2 \mathrm{~N} \mathrm{NaOH}$ and $\mathrm{MeOH}$; (h) $\mathrm{NH}_{3}$ for 27, $\mathrm{HNMe}_{2}$ for 28, WSC, HOBt and DMF; (i) $\mathrm{SnCl}_{2}, \mathrm{NaBH}_{4}$ and $\mathrm{EtOH}$.

the Mitsunobu reaction is robust, 5-(2-aminopyridin-3-yl)-1,3, 4-thiadiazole-2-thiol (a side chain thiol of 24) did not give a desired condensation product. In this case, the thiol was reacted with $(7 R)$ 7-O-methanesulfonyllincomycin $(23)^{10-12}$ in a basic condition to give 24 after an acid treatment (Scheme 2). Compounds 27 and 28 were synthesized by an $\mathrm{S}_{\mathrm{N}} \mathrm{Ar}$ reaction of (7S)-7-deoxy-7-mercaptolincomyicn $(25)^{11}$ and methyl 2-(5-chloro-1,3,4-thiadiazol-2-yl)benzoate followed by hydrolysis of methyl ester (26) and condensation of the corresponding amines. A nitro group of compounds $\mathbf{9 , 1 0}$ and 11 were converted to an amino group by stannous chloride and sodium borohydride to give compounds 29,30 and 31 , respectively.

\section{RESULTS AND DISCUSSION}

We reported that compound 1 exhibited weak antibacterial activities against S. pneumoniae and S. pyogenes with erm gene, although CLDM did not show any activities against those pathogens. ${ }^{10}$ To enhance the antibacterial activities of compound 1, we first changed the benzene ring of compound $\mathbf{1}$ to other aryl and hetero aryl groups as shown in Table 2. Compound 3 having a 2-naphtyl group showed weak antibacterial activities against most of tested pathogens probably due to bulkiness of the substituent based on our three-dimensional analysis. ${ }^{11}$ As for pyridine analogs, antibacterial activities of compounds 4 and 5 against erm-resistant $S$. pneumoniae were comparable to those of compound 1, but compound $\mathbf{6}$ having a 4-pyridyl group showed decreased activities against those pathogens. Compounds $\mathbf{7}$ and $\mathbf{8}$ possessing a thienyl group or a furanyl group showed comparable antibacterial activities against $S$. pneumoniae to compound 1, but decreased activities against $S$. pyogenes with erm gene. On the basis of the results obtained in the above, we performed further optimization focusing on substituents on the benzene ring.

To determine the optimal site of a substituent on the phenyl group, we investigated compounds having a nitro group or an amino group as shown in Table 3. As a matter of fact, compounds having a nitro or an amino group at the ortho position (compounds 9 and 29) exhibited clearly enhanced antibacterial activities against $S$. pneumoniae with erm gene. Similarly, compounds with those groups at the meta position improved the activities (compounds $\mathbf{1 0}$ and 30) but the enhancement effect of the meta substitution seemed to be less than that of the ortho substitution. Antibacterial activities of compounds with a para substituted phenyl group were comparable to those of compound $\mathbf{1}$ against S. pneumoniae with erm gene but stronger than those of compound 1 against $S$. pneumoniae with mef gene. On the other hand, the position of a substituent did not significantly affect antibacterial activities against $S$. pyogenes.

Our finding concerning the ortho substitution at the benzene ring encouraged us to replace the benzene ring with other hetero aromatic rings. Antibacterial activities of compounds having a pyrazole, a pyridine or a pyrazine ring with a nitro or an amino group are shown in Table 4. Although compound $\mathbf{1 4}$ showed improved antibacterial activities against $S$. pneumoniae with erm gene, its antibacterial activities were limited.

We finally examined other substituents on the benzene ring instead of a nitro or an amino group as shown in Table 5. Compounds 16, 18 and 19 have an electron donating group at the ortho position of the benzene ring. Among them, compound $\mathbf{1 6}$ exhibited comparable antibacterial activities to compounds $\mathbf{9}$ and 29 against $S$. pneumoniae 

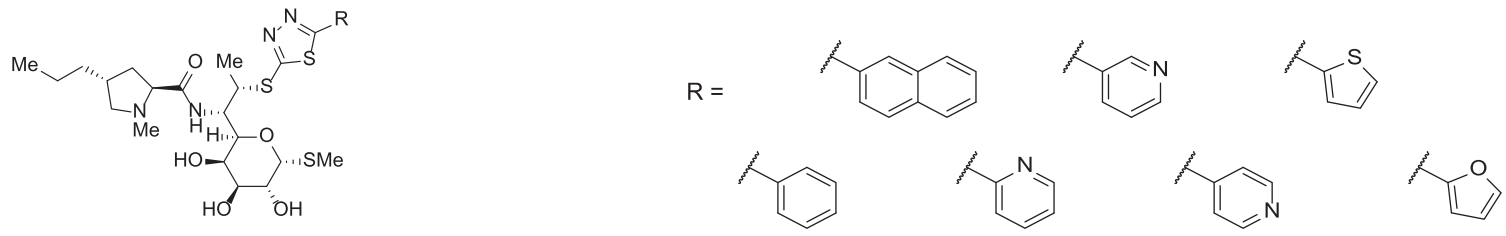

\begin{tabular}{|c|c|c|c|c|c|c|c|c|c|c|}
\hline No. & Test organism ${ }^{\mathrm{b}}$ & Characteristics & 1 & 3 & 4 & 5 & 6 & 7 & 8 & CLDM \\
\hline \multicolumn{3}{|c|}{1 Streptococcus pneumoniae DP1 TypeI susceptible } & 0.13 & 0.5 & 0.06 & 0.06 & 0.06 & 0.06 & 0.03 & 0.13 \\
\hline 2 & S. pneumoniae \#2 & susceptible & 0.06 & 0.5 & 0.06 & 0.06 & 0.13 & 0.06 & 0.03 & 0.13 \\
\hline 3 & S. pneumoniae \#3 & susceptible & 0.06 & 0.5 & 0.06 & 0.03 & 0.06 & 0.06 & 0.03 & 0.13 \\
\hline 4 & S. pneumoniae \#4 & ermB methylase (c) & 64 & 64 & 8 & 32 & $>64$ & 16 & 32 & $>128$ \\
\hline 5 & S. pneumoniae \#5 & ermB methylase (c) & 32 & 64 & 16 & 32 & $>64$ & 64 & 128 & $>128$ \\
\hline 6 & S. pneumoniae \#6 & ermB methylase (c) + mefE & 128 & 64 & 128 & 64 & $>64$ & 128 & 128 & $>128$ \\
\hline 7 & S. pneumoniae \#7 & ermB methylase (i) & 16 & 64 & 32 & 32 & 64 & 32 & 32 & $>128$ \\
\hline 8 & S. pneumoniae \#8 & ermB methylase (i) & 16 & 64 & 32 & 32 & 64 & 64 & 32 & $>128$ \\
\hline 9 & S. pneumoniae \#9 & mefE efflux & 0.06 & 0.25 & 0.06 & 0.03 & 0.06 & 0.06 & 0.03 & 0.13 \\
\hline & S. pneumoniae \#10 & mefE efflux & 0.06 & 0.5 & 0.06 & 0.03 & 0.06 & 0.06 & 0.03 & 0.13 \\
\hline 11 & Streptococcus pyogenes Cook & susceptible & 0.06 & 0.5 & 0.03 & 0.03 & 0.03 & 0.06 & 0.03 & 0.13 \\
\hline & S. pyogenes \#2 & ermB methylase (c) & 4 & 32 & 4 & 16 & 16 & 16 & 16 & $>128$ \\
\hline & S. pyogenes \#3 & mefE efflux & 0.13 & 0.5 & 0.13 & 4 & 0.13 & 0.06 & 0.06 & 0.13 \\
\hline & Haemophilus influenzae \#1 & susceptible & 16 & 128 & 16 & 16 & 16 & 32 & 32 & 8 \\
\hline & H. influenzae \#2 & susceptible & 16 & 32 & 8 & 16 & 8 & 16 & 16 & 8 \\
\hline & H. influenzae \#3 & susceptible & 64 & 128 & 64 & 64 & 64 & 128 & $>128$ & 32 \\
\hline
\end{tabular}

Abbreviations: c, constitutive; CLDM, clindamycin; i, inducible; MIC, minimum inhibitory concentration.

${ }^{a}$ All antibacterial evaluations were performed as hydrochloride. Gray shading strains are target strains.

${ }^{b}$ All strains except standard organisms were clinically isolated.

and S. pyogenes with erm gene. Among the compounds with an electron withdrawing group, compounds 27 and 22 showed comparable antibacterial activities against $S$. pneumoniae and $S$. pyogenes with erm gene to compounds 9 and 29.

\section{CONCLUSIONS}

In summary, we identified compounds $9,16,22,27$ and 29, which exhibited improved antibacterial activities against $S$. pneumoniae and $S$. pyogenes with erm gene by chemical modification of (7S)7-deoxy-7-(5-phenyl-1,3,4-thiadiazol-2-yl-thio)lincomycin (1). These results indicate that a (7S)-7-deoxy-7-[5-(ortho-substituted-phenyl)1,3,4-thiadiazol-2-yl-thio]lincomycin analog is a promising framework to overcome resistant $S$. pneumoniae and $S$. pyogenes. Further structural optimizations are in progress.

\section{EXPERIMENTAL PROCEDURE}

\section{General}

${ }^{1} \mathrm{H}$ nuclear magnetic resonance (NMR) spectra were measured with Varian Gemini-300 (Varian, Palo Alto, CA, USA) for $300 \mathrm{MHz}$, JEOL JNM-GSX 400 (JEOL, Tokyo, Japan) for $400 \mathrm{MHz}$ or BRUKER Ascend 400 NMR spectrometer (BRUKER Corporation, Coventry, UK) for $400 \mathrm{MHz}$ in $\mathrm{CDCl}_{3}$ or $\mathrm{CD}_{3} \mathrm{OD}$ with $0.03 \%$ tetramethylsilane as an internal standard. ${ }^{13} \mathrm{C}$ NMR spectra were measured with BRUKER Ascend 400 NMR spectrometer (BRUKER Corporation) for $100 \mathrm{MHz}$. Mass spectra were obtained on a JEOL JMS-FABmate spectrometer or JEOL JMS-700 mass spectrometer or Agilent Technologies 6530-Q-TOF LC/MS mass spectrometer (Agilent Technologies, Santa Clara, CA, USA). The optical rotations were recorded with Jasco P-2300 digital polarimeter (Jasco, Tokyo, Japan). The melting points were measured with Yanaco MP-S (Yanaco, Tokyo, Japan). The infrared (IR) spectra were measured with Jasco FT/IR-410 (Jasco, Tokyo, Japan). Column chromato- graphy was performed with silica gel 60N (Kanto Chemical, Tokyo, Japan; spherical, neutral).

(7S)-7-Deoxy-7-[5-(2-naphtyl)-1,3,4-thiadiazol-2-ylthio]lincomycin (3) To a solution of compound $2(240 \mathrm{mg}, 0.39 \mathrm{mmol})$ in tetrahydrofuran $(5 \mathrm{ml})$ at $0{ }^{\circ} \mathrm{C}$ were added triphenylphosphine $(160 \mathrm{mg}, 0.61 \mathrm{mmol})$ and diethylazodicarboxylate $(0.1 \mathrm{ml}, 0.55 \mathrm{mmol})$ and stirred at $0{ }^{\circ} \mathrm{C}$ for $30 \mathrm{~min}$, and 5-(naphthalen-2-yl)-1,3,4-thiadiazole-2-thiol $(130 \mathrm{mg}, 0.53 \mathrm{mmol})$ was added and stirred overnight at room temperature. The mixture was concentrated in vacuo and added $\mathrm{MeOH}(5 \mathrm{ml}), 1 \mathrm{~N} \mathrm{HCl}(0.5 \mathrm{ml})$ and stirred at room temperature for $30 \mathrm{~min}$ and concentrated in vacuo. The resulting residue was dissolved in water and washed with diethyl ether. To the mixture was added $\mathrm{NaHCO}_{3}$, and the mixture was extracted with ethyl acetate. The organic phase was washed with water, dried over $\mathrm{MgSO}_{4}$, filtered and concentrated in vacuo. The resulting residue was purified by preparative thin-layer chromatography $\left(\mathrm{CHCl}_{3} / \mathrm{CH}_{3} \mathrm{OH} / 28 \%\right.$ aq $\left.\mathrm{NH}_{4} \mathrm{OH}=20 / 1 / 0.1\right)$ to afford $3(22.3 \mathrm{mg}, 9 \%)$ as colorless solid. $[\alpha]_{\mathrm{D}}{ }^{27}+64^{\circ}\left(\right.$ c $\left.0.79, \mathrm{CHCl}_{3}\right) ;{ }^{1} \mathrm{H} \mathrm{NMR}\left(300 \mathrm{MHz}, \mathrm{CDCl}_{3}\right)$ $\delta 9.03(\mathrm{~d}, J=8.8 \mathrm{~Hz}, 1 \mathrm{H}), 8.31(\mathrm{~s}, 1 \mathrm{H}), 8.04-8.08(\mathrm{~m}, 1 \mathrm{H}), 7.87-8.02(\mathrm{~m}, 3 \mathrm{H})$, 7.56-7.64 (m, 2H), $5.37(\mathrm{~d}, J=5.8 \mathrm{~Hz}, 1 \mathrm{H}), 3.99-4.48(\mathrm{~m}, 1 \mathrm{H}), 4.31-4.37$ (m, $1 \mathrm{H}), 4.28(\mathrm{~d}, J=10.4 \mathrm{~Hz}, 1 \mathrm{H}), 4.16(\mathrm{dd}, J=9.9,6.0 \mathrm{~Hz}, 1 \mathrm{H}), 3.68-3.74$ (m, $1 \mathrm{H}), 3.54-3.64(\mathrm{~m}, 1 \mathrm{H}), 3.42(\mathrm{dd}, J=7.7,5.5 \mathrm{~Hz}, 1 \mathrm{H}), 3.11(\mathrm{dd}, J=9.9$, $4.7 \mathrm{~Hz}, 1 \mathrm{H}), 2.41(\mathrm{~s}, 3 \mathrm{H}), 2.19(\mathrm{~s}, 3 \mathrm{H}), 2.06-2.18(\mathrm{~m}, 2 \mathrm{H}), 1.86-2.02(\mathrm{~m}, 2 \mathrm{H})$, $1.58(\mathrm{~d}, J=6.9 \mathrm{~Hz}, 1 \mathrm{H}), 1.24-1.42(\mathrm{~m}, 4 \mathrm{H})$ and $0.86-0.99(\mathrm{~m}, 3 \mathrm{H})$; MS (FAB) $m / z 633(\mathrm{M}+\mathrm{H})^{+}$; HRMS (ESI) $\mathrm{m} / z$ calcd for $\mathrm{C}_{30} \mathrm{H}_{41} \mathrm{~N}_{4} \mathrm{O}_{5} \mathrm{~S}_{3} 633.2234$, found $633.2235(\mathrm{M}+\mathrm{H})^{+}$.

(7S)-7-Deoxy-7-[5-(2-pyridyl)-1,3,4-thiadiazol-2-ylthio]lincomycin (4) Reaction of 2 (240 mg, $0.39 \mathrm{mmol})$ with 5-(pyridin-2-yl)-1,3,4-thiadiazole2-thiol ( $100 \mathrm{mg}, 0.51 \mathrm{mmol}$ ) gave 4 as a colorless solid in $11 \%$ yield by a similar procedure to $3 .[\alpha]_{\mathrm{D}}{ }^{27}+140^{\circ}\left(\right.$ c $\left.1.2, \mathrm{CHCl}_{3}\right) ;{ }^{1} \mathrm{H} \mathrm{NMR}\left(300 \mathrm{MHz}, \mathrm{CDCl}_{3}\right.$ ) $\delta 8.93(\mathrm{~d}, J=9.1 \mathrm{~Hz}, 1 \mathrm{H}), 8.63-8.67(\mathrm{~m}, 1 \mathrm{H}), 8.28(\mathrm{~d}, J=8.0 \mathrm{~Hz}, 1 \mathrm{H})$, 
Table 3 Antibacterial activities of novel lincomycin derivatives (MIC; $\left.\mu \mathrm{g} \mathrm{ml}^{-1}\right)^{\mathrm{a}}$
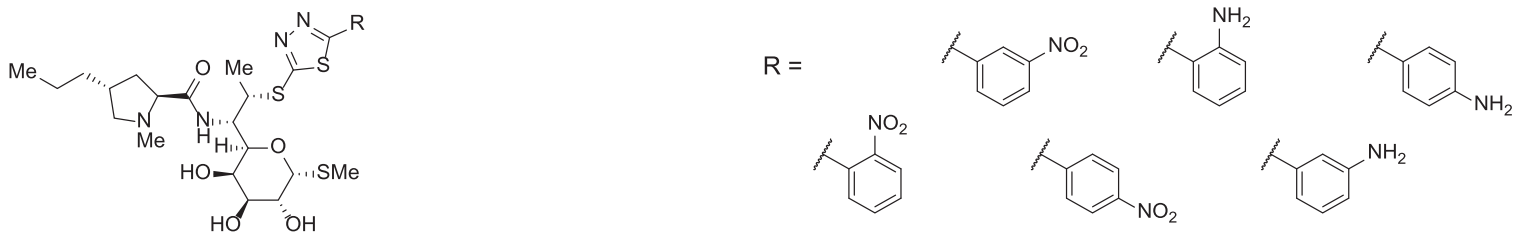

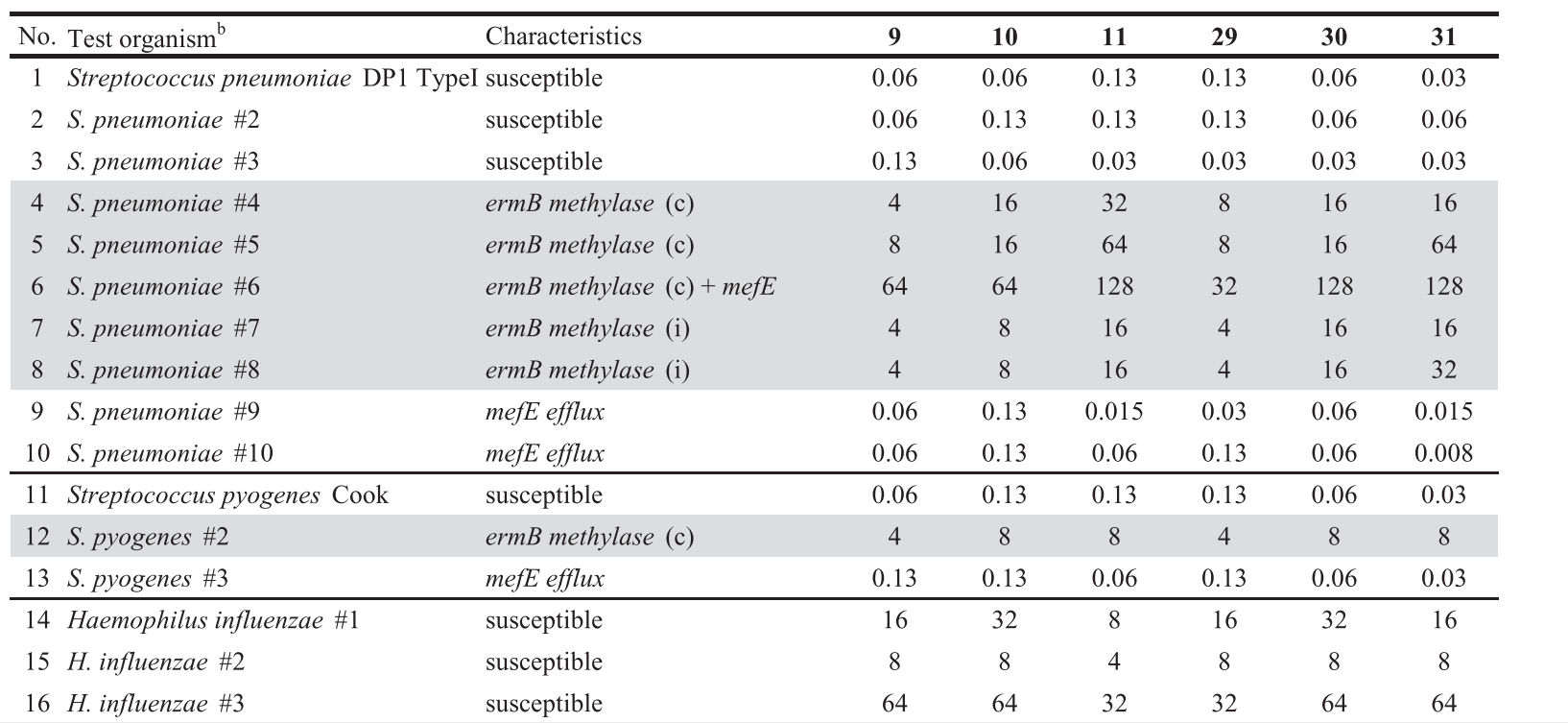

Abbreviations: c, constitutive; i, inducible; MIC, minimum inhibitory concentration.

${ }^{a}$ All antibacterial evaluations were performed as hydrochloride. Gray shading strains are target strains.

All strains except standard organisms were clinically isolated.

7.84-7.91 (m, 1H), 7.38-7.44 (m, 1H), $5.36(\mathrm{~d}, J=5.5 \mathrm{~Hz}, 1 \mathrm{H}), 5.29(\mathrm{~m}, 1 \mathrm{H})$, $4.32-4.47(\mathrm{~m}, 2 \mathrm{H}), 4.25(\mathrm{~d}, J=9.9 \mathrm{~Hz}, 1 \mathrm{H}), 4.10-4.19(\mathrm{~m}, 1 \mathrm{H}), 3.69-3.74$ (m, 1H), 3.55-3.64 (m, 1H), 3.34-3.41 (m, 1H), 3.10 (dd, $J=10.3,4.8 \mathrm{~Hz}, 1 \mathrm{H})$, 2.71-2.79 (m, 1H), 2.41 (s, 3H), 2.15 (s, 3H), 2.06-2.14 (m, 2H), 1.88-2.00 $(\mathrm{m}, 2 \mathrm{H}), 1.57(\mathrm{~d}, J=6.9 \mathrm{~Hz}, 3 \mathrm{H}), 1.28-1.41(\mathrm{~m}, 4 \mathrm{H})$ and $0.88-0.97(\mathrm{~m}, 3 \mathrm{H})$; MS (FAB) $m / z 584(\mathrm{M}+\mathrm{H})^{+}$; HRMS (ESI) $m / z$ calcd for $\mathrm{C}_{25} \mathrm{H}_{38} \mathrm{~N}_{5} \mathrm{O}_{5} \mathrm{~S}_{3}$ 584.2030, found $584.2032(\mathrm{M}+\mathrm{H})^{+}$.

(7S)-7-Deoxy-7-[5-(3-pyridyl)-1,3,4-thiadiazol-2-ylthio]lincomycin (5) Reaction of 2 (240 mg, $0.39 \mathrm{mmol})$ with 5 -(pyridin-3-yl)-1,3,4-thiadiazole2-thiol ( $100 \mathrm{mg}, 0.51 \mathrm{mmol}$ ) gave 5 as a colorless solid in $37 \%$ yield by a similar procedure to 3. $[\alpha]_{\mathrm{D}}{ }^{27}+105^{\circ}$ (c 1.0, $\left.\mathrm{CHCl}_{3}\right) ;{ }^{1} \mathrm{H}$ NMR $\left(300 \mathrm{MHz}, \mathrm{CDCl}_{3}\right)$ $\delta 9.09(\mathrm{~s}, 1 \mathrm{H}), 9.05(\mathrm{~d}, J=8.0 \mathrm{~Hz}, 1 \mathrm{H}), 8.72-8.78(\mathrm{~m}, 1 \mathrm{H}), 8.24(\mathrm{~d}, J=8.2 \mathrm{~Hz}$, $1 \mathrm{H}), 7.42-7.51(\mathrm{~m}, 1 \mathrm{H}), 5.36(\mathrm{~d}, J=5.8 \mathrm{~Hz}, 1 \mathrm{H}), 5.31(\mathrm{br} \mathrm{s}, 1 \mathrm{H}), 4.31-4.50$ $(\mathrm{m}, 2 \mathrm{H}), 4.24(\mathrm{~d}, J=9.9 \mathrm{~Hz}, 1 \mathrm{H}), 4.09-4.19(\mathrm{~m}, 2 \mathrm{H}), 3.69-3.75(\mathrm{~m}, 1 \mathrm{H})$, 3.51-3.61 (m, 1H), 3.36-3.44 (m, 1H), 3.07-3.14 (m, 1H), $2.41(\mathrm{~s}, 3 \mathrm{H}), 2.18$ $(\mathrm{s}, 3 \mathrm{H}), 2.04-2.16(\mathrm{~m}, 2 \mathrm{H}), 1.84-2.02(\mathrm{~m}, 2 \mathrm{H}), 1.57(\mathrm{~d}, J=6.9 \mathrm{~Hz}, 3 \mathrm{H})$, $1.28-1.38(\mathrm{~m}, 4 \mathrm{H})$ and $0.87-0.96(\mathrm{~m}, 3 \mathrm{H})$; MS $(\mathrm{FAB}) \mathrm{m} / \mathrm{z} 584(\mathrm{M}+\mathrm{H})^{+}$; HRMS (ESI) $\mathrm{m} / z$ calcd for $\mathrm{C}_{25} \mathrm{H}_{38} \mathrm{~N}_{5} \mathrm{O}_{5} \mathrm{~S}_{3} 584.2030$, found $584.2027(\mathrm{M}+\mathrm{H})^{+}$.

(7S)-7-Deoxy-7-[5-(4-pyridyl)-1,3,4-thiadiazol-2-ylthio]lincomycin (6) Reaction of 2 (240 mg, $0.39 \mathrm{mmol})$ with 5-(pyridin-4-yl)-1,3,4-thiadiazole2-thiol (100 mg, $0.51 \mathrm{mmol}$ ) gave 6 as a colorless solid in $48 \%$ yield by a similar procedure to $3 .[\alpha]_{\mathrm{D}}{ }^{27}+124^{\circ}\left(c 1.0, \mathrm{CHCl}_{3}\right) ;{ }^{1} \mathrm{H}$ NMR $\left(300 \mathrm{MHz}, \mathrm{CDCl}_{3}\right)$ $\delta 9.03(\mathrm{~d}, J=8.8 \mathrm{~Hz}, 1 \mathrm{H}), 8.75-8.82(\mathrm{~m}, 2 \mathrm{H}), 7.73-7.79(\mathrm{~m}, 2 \mathrm{H}), 5.36$ $(\mathrm{d}, J=5.5 \mathrm{~Hz}, 1 \mathrm{H}), 5.27(\mathrm{br} \mathrm{s}, 1 \mathrm{H}), 4.44-4.54(\mathrm{~m}, 1 \mathrm{H}), 4.39(\mathrm{qd}, J=6.9,3.3 \mathrm{~Hz}$, $1 \mathrm{H}), 4.25$ (d, $J=10.2 \mathrm{~Hz}, 1 \mathrm{H}), 4.17$ (dd, $J=10.2,5.5 \mathrm{~Hz}, 1 \mathrm{H}), 3.77$ (br s, $1 \mathrm{H}$ ), 3.59 (dd, $J=10.2,3.0 \mathrm{~Hz}, 1 \mathrm{H}$ ), 3.43-3.50 (br s $1 \mathrm{H}), 2.51$ (br s, $3 \mathrm{H}$ ), 2.16-2.29 $(\mathrm{m}, 2 \mathrm{H}), 2.15(\mathrm{~s}, 3 \mathrm{H}), 1.89-2.09(\mathrm{~m}, 2 \mathrm{H}), 1.57(\mathrm{~d}, J=6.9 \mathrm{~Hz}, 3 \mathrm{H}), 1.24-1.43$ $(\mathrm{m}, 4 \mathrm{H})$ and $0.87-0.96(\mathrm{~m}, 3 \mathrm{H})$; MS (FAB) $\mathrm{m} / \mathrm{z} 584(\mathrm{M}+\mathrm{H})^{+}$; HRMS (ESI) $\mathrm{m} / \mathrm{z}$ calcd for $\mathrm{C}_{25} \mathrm{H}_{38} \mathrm{~N}_{5} \mathrm{O}_{5} \mathrm{~S}_{3}$ 584.2030, found $584.2032(\mathrm{M}+\mathrm{H})^{+}$.
(7S)-7-Deoxy-7-[5-(2-thienyl)-1,3,4-thiadiazol-2-ylthio]lincomycin (7) Reaction of 2 (240 mg, $0.39 \mathrm{mmol}$ ) with 5-(thiophen-2-yl)-1,3,4-thiadiazole2-thiol (100 mg, $0.50 \mathrm{mmol}$ ) gave 7 as a colorless solid in $17 \%$ yield by a similar procedure to 3. $[\alpha]_{\mathrm{D}}{ }^{30}+90^{\circ}\left(c 1.1, \mathrm{CHCl}_{3}\right) ;{ }^{1} \mathrm{H} \mathrm{NMR}\left(300 \mathrm{MHz}, \mathrm{CDCl}_{3}\right) \delta 8.96$ $(\mathrm{d}, J=8.8 \mathrm{~Hz}, 1 \mathrm{H}), 7.48-7.54(\mathrm{~m}, 2 \mathrm{H}), 7.11-7.16(\mathrm{~m}, 1 \mathrm{H}), 5.34(\mathrm{~d}, J=5.5 \mathrm{~Hz}$, $1 \mathrm{H}), 5.31$ (br s, $1 \mathrm{H}), 4.36-4.46(\mathrm{~m}, 1 \mathrm{H}), 4.22-4.33(\mathrm{~m}, 2 \mathrm{H}), 4.15$ (dd, $J=10.0$, $5.5 \mathrm{~Hz}, 1 \mathrm{H}), 3.68-3.74(\mathrm{~m}, 1 \mathrm{H}), 3.58(\mathrm{dd}, J=10.0,3.4 \mathrm{~Hz}, 1 \mathrm{H}), 3.38(\mathrm{dd}$, $J=7.7,5.5 \mathrm{~Hz}, 1 \mathrm{H}), 3.07(\mathrm{dd}, J=10.2,4.9 \mathrm{~Hz}, 1 \mathrm{H}), 2.37(\mathrm{~s}, 3 \mathrm{H}), 2.17(\mathrm{~s}, 3 \mathrm{H})$, $1.86-2.15(\mathrm{~m}, 4 \mathrm{H}), 1.53(\mathrm{~d}, J=6.9 \mathrm{~Hz}, 3 \mathrm{H}), 1.28-1.39(\mathrm{~m}, 4 \mathrm{H})$ and $0.86-0.96$ $(\mathrm{m}, 3 \mathrm{H})$; MS (FAB) $\mathrm{m} / \mathrm{z} 589(\mathrm{M}+\mathrm{H})^{+}$; HRMS (ESI) $\mathrm{m} / \mathrm{z}$ calcd for $\mathrm{C}_{24} \mathrm{H}_{37} \mathrm{~N}_{4} \mathrm{O}_{5} \mathrm{~S}_{4}$ 589.1641, found $589.1646(\mathrm{M}+\mathrm{H})^{+}$.

\section{(7S)-7-Deoxy-7-[5-(2-furanyl)-1,3,4-thiadiazol-2-ylthio]lincomycin} (8)

Reaction of 2 (240 mg, $0.39 \mathrm{mmol})$ with 5-(furan-2-yl)-1,3,4-thiadiazole-2thiol (100 mg, $0.54 \mathrm{mmol}$ ) gave $\mathbf{8}$ as a colorless solid in $38 \%$ yield by a similar procedure to $3 .[\alpha]_{\mathrm{D}}{ }^{30}+88^{\circ}\left(\mathrm{c} 1.4, \mathrm{CHCl}_{3}\right) ;{ }^{1} \mathrm{H} \mathrm{NMR}\left(300 \mathrm{MHz}, \mathrm{CDCl}_{3}\right) \delta 8.79$ (d, $J=8.5 \mathrm{~Hz}, 1 \mathrm{H}), 7.58-7.62(\mathrm{~m}, 1 \mathrm{H}), 7.13-7.17(\mathrm{~m}, 1 \mathrm{H}), 6.57-6.63(\mathrm{~m}, 1 \mathrm{H})$, $5.34(\mathrm{~d}, J=5.5 \mathrm{~Hz}, 1 \mathrm{H}), 5.26$ (br s, $1 \mathrm{H}), 4.35-4.44(\mathrm{~m}, 1 \mathrm{H}), 4.31$ (qd, $J=6.9$, $3.3 \mathrm{~Hz}, 1 \mathrm{H}), 4.24(\mathrm{~d}, J=10.2 \mathrm{~Hz}, 1 \mathrm{H}), 4.11-4.21(\mathrm{~m}, 2 \mathrm{H}), 3.67-3.74(\mathrm{~m}, 1 \mathrm{H})$, 3.53-3.64 (m, 2H), $3.47(\mathrm{~s}, 1 \mathrm{H}), 3.29-3.39(\mathrm{~m}, 1 \mathrm{H}), 3.06(\mathrm{dd}, J=10.0,4.5 \mathrm{~Hz}$, $1 \mathrm{H}), 2.36(\mathrm{~s}, 3 \mathrm{H}), 2.14(\mathrm{~s}, 3 \mathrm{H}), 2.02-2.11(\mathrm{~m}, 2 \mathrm{H}), 185-1.99(\mathrm{~m}, 2 \mathrm{H}), 1.51$ $(\mathrm{d}, J=6.9 \mathrm{~Hz}, 3 \mathrm{H}), 1.11-1.40(\mathrm{~m}, 4 \mathrm{H})$ and $0.82-0.97(\mathrm{~m}, 3 \mathrm{H})$; MS (FAB) $\mathrm{m} / \mathrm{z}$ $573(\mathrm{M}+\mathrm{H})^{+}$; HRMS (ESI) $\mathrm{m} / z$ calcd for $\mathrm{C}_{24} \mathrm{H}_{37} \mathrm{~N}_{4} \mathrm{O}_{6} \mathrm{~S}_{3}$ 573.1870, found $573.1870(\mathrm{M}+\mathrm{H})^{+}$.

\section{(7S)-7-Deoxy-7-[5-(2-nitrophenyl)-1,3,4-thiadiazol-2-ylthio] lincomycin (9)}

Reaction of 2 (320 mg, $0.51 \mathrm{mmol}$ ) with 5-(2-nitrophenyl)-1,3,4-thiadiazole-2thiol $(160 \mathrm{mg}, 0.67 \mathrm{mmol}$ ) gave 9 as a colorless solid in $54 \%$ yield by a similar 


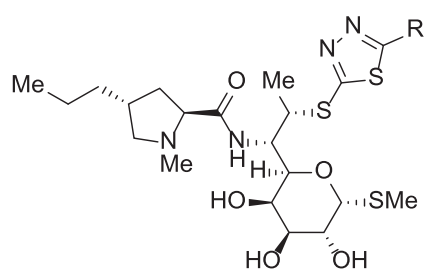<smiles></smiles>

\begin{tabular}{|c|c|c|c|c|c|c|c|}
\hline No. & 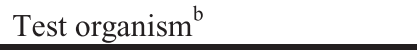 & Characteristics & 12 & 13 & 14 & 24 & 15 \\
\hline 1 & \multicolumn{2}{|c|}{ Streptococcus pneumoniae DP1 TypeI susceptible } & 0.03 & 0.03 & 0.03 & 0.03 & 0.015 \\
\hline 2 & S. pneumoniae \#2 & susceptible & 0.03 & 0.03 & 0.03 & 0.06 & 0.03 \\
\hline 3 & S. pneumoniae \#3 & susceptible & 0.03 & 0.015 & 0.03 & 0.03 & 0.015 \\
\hline 4 & S. pneumoniae \#4 & ermB methylase (c) & 32 & 2 & 8 & 4 & 8 \\
\hline 5 & S. pneumoniae \#5 & ermB methylase (c) & 64 & 32 & 8 & 16 & 16 \\
\hline 6 & S. pneumoniae \#6 & ermB methylase $(\mathrm{c})+$ mefE & 128 & 128 & 64 & 64 & 64 \\
\hline 7 & S. pneumoniae \#7 & ermB methylase (i) & 16 & 16 & 4 & ND & 4 \\
\hline 8 & S. pneumoniae \#8 & ermB methylase (i) & 32 & 8 & 4 & 8 & 8 \\
\hline 9 & S. pneumoniae \#9 & mefE efflux & 0.03 & 0.03 & 0.03 & 0.06 & $\leqq 0.008$ \\
\hline 10 & S. pneumoniae \#10 & mefE efflux & 0.06 & 0.03 & 0.03 & 0.06 & 0.015 \\
\hline 11 & Streptococcus pyogenes Cook & susceptible & 0.03 & 0.03 & 0.03 & 0.06 & 0.015 \\
\hline & S. pyogenes \#2 & ermB methylase (c) & 8 & 8 & 4 & 8 & 4 \\
\hline 13 & S. pyogenes \#3 & mefE efflux & 0.03 & 0.03 & 0.06 & 0.06 & 0.03 \\
\hline 14 & Haemophilus influenzae \#1 & susceptible & 32 & 32 & 8 & 16 & ND \\
\hline & H. influenzae \#2 & susceptible & 16 & 16 & 4 & 16 & 4 \\
\hline & H. influenzae \#3 & susceptible & 64 & 64 & 32 & 64 & 32 \\
\hline
\end{tabular}

Abbreviations: c, constitutive; i, inducible; MIC, minimum inhibitory concentration; ND, not determined.

${ }^{a} \mathrm{All}$ antibacterial evaluations were performed as hydrochloride. Gray shading strains are target strains.

${ }^{b}$ All strains except standard organisms were clinically isolated.

procedure to 3. $\mathrm{mp} 235-240{ }^{\circ} \mathrm{C}$ (decomp.); $[\alpha]_{\mathrm{D}}{ }^{30}+91^{\circ}\left(\right.$ c $\left.0.52, \mathrm{CHCl}_{3}\right) ; \mathrm{IR}$ (KBr) 3399, 2922, 1654 and $1533 \mathrm{~cm}^{-1}$; ${ }^{1} \mathrm{H} \mathrm{NMR}\left(300 \mathrm{MHz}, \mathrm{CDCl}_{3}\right) \delta 9.10$ $(\mathrm{d}, J=8.0 \mathrm{~Hz}, 1 \mathrm{H}), 7.68-7.79(\mathrm{~m}, 1 \mathrm{H}), 7.68-7.79(\mathrm{~m}, 3 \mathrm{H}), 5.36(\mathrm{~d}, J=5.5 \mathrm{~Hz}$, $1 \mathrm{H}), 4.39-4.49(\mathrm{~m}, 1 \mathrm{H}), 4.20-4.38(\mathrm{~m}, 2 \mathrm{H}), 4.15$ (dd, $J=9.9,5.5 \mathrm{~Hz}, 1 \mathrm{H}), 3.71$ (br s, $1 \mathrm{H}), 3.53-3.61(\mathrm{~m}, 1 \mathrm{H}), 3.31-3.38(\mathrm{~m}, 1 \mathrm{H}), 3.09$ (dd, $J=10.3,4.8 \mathrm{~Hz}$, $1 \mathrm{H}), 2.40(\mathrm{~s}, 3 \mathrm{H}), 2.19(\mathrm{~s}, 3 \mathrm{H}), 2.03-2.16(\mathrm{~m}, 4 \mathrm{H}), 1.57(\mathrm{~d}, J=7.1 \mathrm{~Hz}, 3 \mathrm{H})$, $1.24-1.40(\mathrm{~m}, 4 \mathrm{H})$ and $0.86-0.96(\mathrm{~m}, 3 \mathrm{H}) ;{ }^{13} \mathrm{C}$ NMR $\left(100 \mathrm{MHz}, \mathrm{CDCl}_{3}\right)$ $\delta 179.1,164.9,163.5,148.5,132.9,132.0,131.6,124.9,123.8,89.1,71.8,71.0$, $69.2,68.4,68.2,62.5,53.0,44.9,41.7,38.1,37.9,35.7,21.5,18.5,14.8$ and 14.2; MS (FAB) $\mathrm{m} / z 628(\mathrm{M}+\mathrm{H})^{+}$; HRMS (ESI) $\mathrm{m} / z$ calcd for $\mathrm{C}_{26} \mathrm{H}_{38} \mathrm{~N}_{5} \mathrm{O}_{7} \mathrm{~S}_{3}$ 628.1928, found $628.1934(\mathrm{M}+\mathrm{H})^{+}$.

(7S)-7-Deoxy-7-[5-(3-nitrophenyl)-1,3,4-thiadiazol-2-ylthio] lincomycin (10)

Reaction of 2 (320 mg, $0.51 \mathrm{mmol})$ with 5-(3-nitrophenyl)-1,3,4-thiadiazole2-thiol (160 mg, $0.67 \mathrm{mmol}$ ) gave 10 as a colorless solid in $41 \%$ yield by a similar procedure to $\left.3 .[\alpha]_{\mathrm{D}}{ }^{30}+85^{\circ}(c) 1.1, \mathrm{CHCl}_{3}\right) ;{ }^{1} \mathrm{H} \mathrm{NMR}(300 \mathrm{MHz}$, $\left.\mathrm{CDCl}_{3}\right) \delta 9.02(\mathrm{~d}, J=9.1 \mathrm{~Hz}, 1 \mathrm{H}), 8.07-8.75(\mathrm{~m}, 1 \mathrm{H}), 8.35-8.42(\mathrm{~m}, 1 \mathrm{H})$, $8.24-8.29(\mathrm{~m}, 1 \mathrm{H}), 7.73(\mathrm{t}, J=8.0 \mathrm{~Hz}, 1 \mathrm{H}), 5.36(\mathrm{~d}, J=5.2 \mathrm{~Hz}, 1 \mathrm{H}), 5.31$ (br s, $1 \mathrm{H}), 4.34-4.52(\mathrm{~m}, 2 \mathrm{H}), 4.23(\mathrm{~d}, J=10.2 \mathrm{~Hz}, 1 \mathrm{H}), 4.15$ (dd, $J=10.0$, $5.4 \mathrm{~Hz}, 1 \mathrm{H}), 3.69-3.75(\mathrm{~m}, 1 \mathrm{H}), 3.57(\mathrm{dd}, J=9.9,3.0 \mathrm{~Hz}, 1 \mathrm{H}), 3.36-3.44$ $(\mathrm{m}, 1 \mathrm{H}), 3.11(\mathrm{dd}, J=10.0,4.8 \mathrm{~Hz}, 1 \mathrm{H}), 2.43(\mathrm{~s}, 3 \mathrm{H}), 2.18(\mathrm{~s}, 3 \mathrm{H}), 2.08-2.17$ $(\mathrm{m}, 2 \mathrm{H}), 1.90-2.03(\mathrm{~m}, 2 \mathrm{H}), 1.58(\mathrm{~d}, J=6.9 \mathrm{~Hz}, 3 \mathrm{H}), 1.24-1.44(\mathrm{~m}, 4 \mathrm{H})$ and $0.88-0.99(\mathrm{~m}, 3 \mathrm{H})$; MS (FAB) $\mathrm{m} / z 628(\mathrm{M}+\mathrm{H})^{+}$; HRMS (ESI) $\mathrm{m} / z$ calcd for $\mathrm{C}_{26} \mathrm{H}_{38} \mathrm{~N}_{5} \mathrm{O}_{7} \mathrm{~S}_{3} 628.1928$, found $628.1938(\mathrm{M}+\mathrm{H})^{+}$.
(7S)-7-Deoxy-7-[5-(4-nitrophenyl)-1,3,4-thiadiazol-2-ylthio] lincomycin (11)

Reaction of 2 (240 mg, $0.39 \mathrm{mmol})$ with 5-(4-nitrophenyl)-1,3,4-thiadiazole2-thiol $(120 \mathrm{mg}, 0.50 \mathrm{mmol})$ gave 11 as a colorless solid in $33 \%$ yield by a similar procedure to $3 .[\alpha]_{\mathrm{D}}{ }^{30}+67^{\circ}\left(c \quad 0.81, \mathrm{CHCl}_{3}\right) ;{ }^{1} \mathrm{H} \mathrm{NMR}(300 \mathrm{MHz}$, $\left.\mathrm{CDCl}_{3}\right) \delta 8.92(\mathrm{~d}, J=9.1 \mathrm{~Hz}, 1 \mathrm{H}), 8.35(\mathrm{~d}, J=8.5 \mathrm{~Hz}, 2 \mathrm{H}), 8.08(\mathrm{~d}, J=8.5 \mathrm{~Hz}$, $2 \mathrm{H}), 5.34(\mathrm{~d}, J=5.5 \mathrm{~Hz}, 1 \mathrm{H}), 4.34-4.51(\mathrm{~m}, 2 \mathrm{H}), 4.22(\mathrm{~d}, J=9.9 \mathrm{~Hz}, 1 \mathrm{H}), 4.16$ (dd, $J=10.3,5.6 \mathrm{~Hz}, 1 \mathrm{H}), 3.72(\mathrm{~d}, J=3.0 \mathrm{~Hz}, 1 \mathrm{H}), 3.58(\mathrm{dd}, J=10.0,3.3 \mathrm{~Hz}$, $1 \mathrm{H}), 3.33-3.39$ (m, $1 \mathrm{H}), 3.11$ (dd, $J=10.0,4.5 \mathrm{~Hz}, 1 \mathrm{H}), 2.41$ (s, 3H), 2.14 (s, 3H), 2.06-2.12 (m, 2H), 1.86-2.04 (m, $2 \mathrm{H}), 1.57(\mathrm{~d}, J=6.9 \mathrm{~Hz}, 3 \mathrm{H})$, 1.23-1.38 (m, 4H) and 0.85-0.94 (m, 3H); MS (FAB) $m / z 628(\mathrm{M}+\mathrm{H})^{+}$; HRMS (ESI) $m / z$ calcd for $\mathrm{C}_{26} \mathrm{H}_{38} \mathrm{~N}_{5} \mathrm{O}_{7} \mathrm{~S}_{3} 628.1928$, found $628.1927(\mathrm{M}+\mathrm{H})^{+}$.

(7S)-7-Deoxy-7-[5-(1-methyl-5-nitro-1H-pyrazol-4-yl)-1,3,4thiadiazol-2-ylthio]lincomycin (12)

Reaction of 2 ( $280 \mathrm{mg}, 0.45 \mathrm{mmol}$ ) with 5-(1-methyl-5-nitro-1H-pyrazol-4-yl)1,3,4-thiadiazole-2-thiol $(120 \mathrm{mg}, 0.49 \mathrm{mmol})$ gave 12 as a colorless solid in $35 \%$ yield by a similar procedure to 3 . $[\alpha]_{\mathrm{D}}{ }^{31}+51^{\circ}\left(c 1.1, \mathrm{CHCl}_{3}\right) ;{ }^{1} \mathrm{H}$ NMR $\left(300 \mathrm{MHz}, \mathrm{CDCl}_{3}\right) \delta 8.89(\mathrm{~d}, J=8.8 \mathrm{~Hz}, 1 \mathrm{H}), 5.34(\mathrm{~d}, J=5.5 \mathrm{~Hz}, 1 \mathrm{H}), 5.27$ (br s, $1 \mathrm{H}), 4.37-4.48(\mathrm{~m}, 2 \mathrm{H}), 4.23(\mathrm{~d}, J=10.4 \mathrm{~Hz}, 1 \mathrm{H}), 4.14$ (dd, $J=10.0$, $5.5 \mathrm{~Hz}, 1 \mathrm{H}), 4.08(\mathrm{~s}, 3 \mathrm{H}), 3.70$ (br s, $1 \mathrm{H}), 3.53-3.62(\mathrm{~m}, 1 \mathrm{H}), 3.32-3.40$ (m, $1 \mathrm{H}), 3.09$ (dd, $J=10.3,4.8 \mathrm{~Hz}, 1 \mathrm{H}), 2.40(\mathrm{~s}, 3 \mathrm{H}), 2.17$ (s, 3H), 1.85-2.15 $(\mathrm{m}, 4 \mathrm{H}), 1.55(\mathrm{~d}, J=6.9 \mathrm{~Hz}, 1 \mathrm{H}), 1.25-1.39(\mathrm{~m}, 4 \mathrm{H})$ and $0.85-0.96(\mathrm{~m}, 3 \mathrm{H})$; MS (FAB) $\mathrm{m} / z$ $632(\mathrm{M}+\mathrm{H})^{+}$; HRMS (ESI) $\mathrm{m} / z$ calcd for $\mathrm{C}_{24} \mathrm{H}_{38} \mathrm{~N}_{7} \mathrm{O}_{7} \mathrm{~S}_{3}$ 632.1989, found 632.1991 $(\mathrm{M}+\mathrm{H})^{+}$. 


\begin{tabular}{|c|c|c|c|c|c|c|c|c|c|c|c|}
\hline No. & 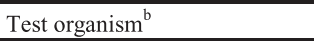 & characteristics & 16 & 17 & 18 & 19 & 20 & 21 & 27 & 28 & 22 \\
\hline 1 & \multicolumn{2}{|c|}{ Streptococcus pneumoniae DP1 TypeI susceptible } & 0.06 & 0.13 & 0.13 & 0.25 & 0.13 & 0.06 & 0.06 & 0.06 & 0.06 \\
\hline 2 & S. pneumoniae \#2 & susceptible & 0.13 & 0.25 & 0.13 & 0.25 & 0.13 & 0.13 & 0.06 & 0.06 & 0.06 \\
\hline 3 & S. pneumoniae \#3 & susceptible & 0.13 & 0.25 & 0.13 & 0.25 & 0.13 & 0.13 & 0.06 & 0.06 & 0.06 \\
\hline 4 & S. pneumoniae \#4 & ermB methylase (c) & ND & 128 & 4 & 64 & 16 & 64 & 8 & 16 & 1 \\
\hline 5 & S. pneumoniae \#5 & ermB methylase (c) & 8 & 128 & 8 & 16 & 16 & 16 & 8 & 16 & 4 \\
\hline 6 & S. pneumoniae \#6 & ermB methylase (c) + mefE & 32 & $>128$ & 128 & 128 & 128 & 128 & 32 & 64 & 32 \\
\hline 7 & S. pneumoniae \#7 & ermB methylase (i) & 4 & 16 & 8 & 16 & 16 & 16 & 1 & 2 & 4 \\
\hline 8 & S. pneumoniae \#8 & ermB methylase (i) & 4 & 32 & N.D. & 16 & 16 & 16 & 1 & 2 & 4 \\
\hline 9 & S. pneumoniae \#9 & mefE efflux & 0.06 & 0.13 & 0.06 & 0.13 & 0.06 & 0.06 & 0.03 & 0.015 & 0.06 \\
\hline 10 & S. pneumoniae \#10 & mefE efflux & 0.13 & 0.13 & 0.13 & 0.06 & 0.13 & 0.13 & 0.06 & 0.06 & 0.06 \\
\hline 11 & Streptococcus pyogenes Cook & susceptible & 0.13 & 0.13 & 0.13 & 0.25 & 0.13 & 0.06 & 0.06 & 0.06 & 0.06 \\
\hline 12 & S. pyogenes \#2 & ermB methylase (c) & 4 & 32 & 8 & 16 & 16 & 8 & 4 & 4 & 4 \\
\hline 13 & S. pyogenes \#3 & mefE efflux & 0.13 & 0.25 & 0.13 & 0.13 & 0.25 & 0.13 & 0.06 & 0.06 & 0.13 \\
\hline 14 & Haemophilus influenzae \#1 & susceptible & 32 & 128 & 32 & 64 & 128 & 16 & 16 & 16 & 16 \\
\hline 15 & H. influenzae \#2 & susceptible & 16 & 128 & 16 & 32 & 32 & 16 & 16 & 16 & 16 \\
\hline 16 & H. influenzae \#3 & susceptible & 32 & $>128$ & 64 & 128 & 128 & 64 & 32 & 64 & 64 \\
\hline
\end{tabular}

Abbreviations: c, constitutive; i, inducible; MIC, minimum inhibitory concentration; ND, not determined.

${ }^{a}$ All antibacterial evaluations were performed as hydrochloride. Gray shading strains are target strains.

${ }^{\mathrm{b} A l l}$ strains except standard organisms were clinically isolated.

(7S)-7-Deoxy-7-[5-(1-methyl-4-nitro-1H-pyrazol-3-yl)-1,3,4thiadiazol-2-ylthio]lincomycin (13)

Reaction of 2 ( $280 \mathrm{mg}, 0.45 \mathrm{mmol})$ with 5-(1-methyl-4-nitro-1H-pyrazol-3-yl)1,3,4-thiadiazole-2-thiol $(120 \mathrm{mg}, 0.49 \mathrm{mmol})$ gave 13 as a colorless solid in $18 \%$ yield by a similar procedure to $3 .[\alpha]_{\mathrm{D}}^{30}+79^{\circ}\left(\right.$ c $\left.0.52, \mathrm{CHCl}_{3}\right) ;{ }^{1} \mathrm{H} \mathrm{NMR}$ $\left(300 \mathrm{MHz}, \mathrm{CDCl}_{3}\right) \delta 8.90(\mathrm{~d}, J=8.8 \mathrm{~Hz}, 1 \mathrm{H}), 8.33(\mathrm{~s}, 1 \mathrm{H}), 5.35(\mathrm{~d}, J=5.5 \mathrm{~Hz}$, $1 \mathrm{H}), 5.30$ (br s, $1 \mathrm{H}), 4.37-4.49(\mathrm{~m}, 2 \mathrm{H}), 4.23(\mathrm{~d}, J=10.4 \mathrm{~Hz}, 1 \mathrm{H}), 4.10-4.20$ $(\mathrm{m}, 2 \mathrm{H}), 4.08(\mathrm{~s}, 3 \mathrm{H}), 3.67-3.76(\mathrm{~m} 2 \mathrm{H}), 3.52-3.63(\mathrm{~m}, 2 \mathrm{H}), 3.49(\mathrm{~s}, 1 \mathrm{H})$, 3.29-3.44 (m, 2H), 3.09 (dd, $J=10.3,4.3 \mathrm{~Hz}, 1 \mathrm{H}), 2.83-2.95(\mathrm{~m}, 1 \mathrm{H}), 2.69$ $(\mathrm{d}, J=7.7 \mathrm{~Hz}, 1 \mathrm{H}), 2.41(\mathrm{~s}, 3 \mathrm{H}), 2.14(\mathrm{~s}, 3 \mathrm{H}), 2.04-2.13(\mathrm{~m}, 2 \mathrm{H}), 1.79-2.00$ $(\mathrm{m}, 2 \mathrm{H}), 1.56(\mathrm{~d}, J=7.1 \mathrm{~Hz}, 3 \mathrm{H}), 1.27-1.38(\mathrm{~m}, 4 \mathrm{H})$ and $0.86-0.95(\mathrm{~m}, 3 \mathrm{H})$; MS (FAB) $m / z 632(\mathrm{M}+\mathrm{H})^{+}$; HRMS (ESI) $\mathrm{m} / z$ calcd for $\mathrm{C}_{24} \mathrm{H}_{38} \mathrm{~N}_{7} \mathrm{O}_{7} \mathrm{~S}_{3}$ 632.1989, found $632.1982(\mathrm{M}+\mathrm{H})^{+}$.

(7S)-7-[5-(5-Amino-1-methyl-1H-pyrazol-4-yl)-1,3,4-thiadiazol-2ylthio]-7-deoxylincomycin (14)

Reaction of 2 ( $240 \mathrm{mg}, 0.39 \mathrm{mmol})$ with 5-(5-amino-1-methyl-1H-pyrazol4-yl)-1,3,4-thiadiazole-2-thiol (115 mg, $0.54 \mathrm{mmol}$ ) gave $\mathbf{1 4}$ as a colorless solid in $65 \%$ yield by a similar procedure to $3 .[\alpha]_{\mathrm{D}}^{30}+88^{\circ}\left(c 1.0, \mathrm{CHCl}_{3}\right) ;{ }^{1} \mathrm{H}$ NMR $\left(300 \mathrm{MHz}, \mathrm{CDCl}_{3}\right) \delta 8.71(\mathrm{~d}, J=8.2 \mathrm{~Hz}, 1 \mathrm{H}), 7.46(\mathrm{~s}, 1 \mathrm{H}), 5.38($ br s, $1 \mathrm{H}), 5.34$ (d, $J=5.5 \mathrm{~Hz}, 1 \mathrm{H}), 5.23(\mathrm{br} \mathrm{s}, 1 \mathrm{H}), 4.33-4.44(\mathrm{~m}, 1 \mathrm{H}), 4.21-4.32(\mathrm{~m}, 2 \mathrm{H}), 4.14$ $(\mathrm{dd}, J=10.0,5.5 \mathrm{~Hz}, 1 \mathrm{H}), 3.70(\mathrm{~s}, 3 \mathrm{H}), 3.55(\mathrm{~m}, 1 \mathrm{H}), 3.26-3.33(\mathrm{~m}, 1 \mathrm{H})$, 3.07 (dd, $J=10.0,4.5 \mathrm{~Hz}, 1 \mathrm{H}), 2.35(\mathrm{~s}, 3 \mathrm{H}), 2.15(\mathrm{~s}, 3 \mathrm{H}), 2.03-2.14(\mathrm{~m}, 2 \mathrm{H})$, $1.85-2.01(\mathrm{~m}, 2 \mathrm{H}), 1.49(\mathrm{~d}, J=7.1 \mathrm{~Hz}, 3 \mathrm{H}), 1.25-1.38(\mathrm{~m}, 4 \mathrm{H})$ and $0.86-0.97$ $(\mathrm{m}, 3 \mathrm{H})$; MS (FAB) $\mathrm{m} / \mathrm{z} 602(\mathrm{M}+\mathrm{H})^{+}$; HRMS (ESI) $\mathrm{m} / \mathrm{z}$ calcd for $\mathrm{C}_{24} \mathrm{H}_{40} \mathrm{~N}_{7} \mathrm{O}_{5} \mathrm{~S}_{3}$ 602.2248, found $602.2243(\mathrm{M}+\mathrm{H})^{+}$.

(7S)-7-[5-(3-Aminopyrazin-2-yl)-1,3,4-thiadiazol-2-ylthio]-7deoxylincomycin (15)

Reaction of 2 ( $240 \mathrm{mg}, 0.39 \mathrm{mmol})$ with 5-(3-aminopyrazin-2-yl)-1,3,4-thiadiazole-2-thiol ( $140 \mathrm{mg}, 0.66 \mathrm{mmol}$ ) gave 15 as a colorless solid in $59 \%$ yield by a similar procedure to $3 .[\alpha]_{\mathrm{D}}{ }^{30}+62^{\circ}\left(c 1.0, \mathrm{CHCl}_{3}\right) ;{ }^{1} \mathrm{H} \mathrm{NMR}(300 \mathrm{MHz}$, $\left.\mathrm{CDCl}_{3}\right) \delta 8.74(\mathrm{~d}, J=8.8 \mathrm{~Hz}, 1 \mathrm{H}), 8.11(\mathrm{~d}, J=2.4 \mathrm{~Hz}, 1 \mathrm{H}), 7.94(\mathrm{~d}, J=2.4 \mathrm{~Hz}$, $1 \mathrm{H}), 5.34(\mathrm{~d}, J=5.5 \mathrm{~Hz}, 1 \mathrm{H}), 5.20($ br $\mathrm{s}, 1 \mathrm{H}), 4.33-4.52(\mathrm{~m}, 2 \mathrm{H}), 4.22$ (d, $J=10.2 \mathrm{~Hz}, 1 \mathrm{H}), 4.17(\mathrm{dd}, J=10.5,5.5 \mathrm{~Hz}, 1 \mathrm{H}), 3.67-3.75(\mathrm{~m}, 1 \mathrm{H}), 3.60$ (dd, $J=10.2,3.3 \mathrm{~Hz}, 1 \mathrm{H}), 3.23-3.32(\mathrm{~m}, 1 \mathrm{H}), 3.09$ (dd, $J=10.0,4.5 \mathrm{~Hz}, 1 \mathrm{H})$, $2.39(\mathrm{~s}, 3 \mathrm{H}), 2.10(\mathrm{~s}, 3 \mathrm{H}), 1.84(\mathrm{~m}, 2 \mathrm{H}), 1.56(\mathrm{~d}, J=6.9 \mathrm{~Hz}, 3 \mathrm{H}), 1.20-1.40$ $(\mathrm{m}, 4 \mathrm{H})$ and $0.85-0.96(\mathrm{~m}, 3 \mathrm{H})$; MS (FAB) $\mathrm{m} / z 600(\mathrm{M}+\mathrm{H})^{+}$; HRMS (ESI) $\mathrm{m} / \mathrm{z}$ calcd for $\mathrm{C}_{24} \mathrm{H}_{38} \mathrm{~N}_{7} \mathrm{O}_{5} \mathrm{~S}_{3} 600.2091$, found $600.2092(\mathrm{M}+\mathrm{H})^{+}$.

(7S)-7-Deoxy-7-\{5-[2-(methylamino)phenyl]-1,3,4-thiadiazol-2ylthio\}lincomycin (16)

Reaction of 2 (160 mg, $0.26 \mathrm{mmol}$ ) with 5-[2-(methylamino)phenyl]-1,3, 4-thiadiazole-2-thiol (100 mg, $0.45 \mathrm{mmol}$ ) gave 16 as a colorless solid in $22 \%$ yield by a similar procedure to $3 .[\alpha]_{\mathrm{D}}{ }^{31}+55^{\circ}\left(c 1.1, \mathrm{CHCl}_{3}\right) ;{ }^{1} \mathrm{H} \mathrm{NMR}$ $\left(300 \mathrm{MHz}, \mathrm{CDCl}_{3}\right) \delta 8.85(\mathrm{~d}, J=9.1 \mathrm{~Hz}, 1 \mathrm{H}), 8.09-8.21(\mathrm{~m}, 1 \mathrm{H}), 7.27-7.45$ (m, 2H), 6.63-6.85 (m, 2H), 5.35 (d, $J=5.5 \mathrm{~Hz}, 1 \mathrm{H}), 5.26$ (br s, $1 \mathrm{H}), 4.38-4.51$ $(\mathrm{m}, 1 \mathrm{H}), 4.22-4.36(\mathrm{~m}, 2 \mathrm{H}), 4.17(\mathrm{dd}, J=9.9,5.5 \mathrm{~Hz}, 1 \mathrm{H}), 3.68-3.77(\mathrm{~m}, 1 \mathrm{H})$, 3.60 (dd, $J=10.0,3.4 \mathrm{~Hz}, 1 \mathrm{H}), 3.24-3.36(\mathrm{~m}, 1 \mathrm{H}), 3.04-3.13(\mathrm{~m}, 1 \mathrm{H}), 3.00$ (d, $J=4.9 \mathrm{~Hz}, 3 \mathrm{H}), 2.38$ (s, 3H), $2.14(\mathrm{~s}, 3 \mathrm{H}), 1.88-2.12(\mathrm{~m}, 4 \mathrm{H}), 1.54$ (d, $J=6.9 \mathrm{~Hz}, 3 \mathrm{H}), 1.25-1.40(\mathrm{~m}, 4 \mathrm{H})$ and $0.85-0.97(\mathrm{~m}, 3 \mathrm{H})$; MS (FAB) $\mathrm{m} / z$ $612(\mathrm{M}+\mathrm{H})^{+}$; HRMS (ESI) $\mathrm{m} / z$ calcd for $\mathrm{C}_{27} \mathrm{H}_{42} \mathrm{~N}_{5} \mathrm{O}_{5} \mathrm{~S}_{3}$ 612.2343, found $612.2339(\mathrm{M}+\mathrm{H})^{+}$.

\section{(7S)-7-[5-(2-Chlorophenyl)-1,3,4-thiadiazol-2-ylthio]-7-}

\section{deoxylincomycin (17)}

Reaction of 2 (240 mg, $0.39 \mathrm{mmol})$ with 5-(2-chlorophenyl)-1,3,4-thiadiazole2-thiol (100 mg, $0.44 \mathrm{mmol}$ ) gave 17 as a colorless solid in $34 \%$ yield by a similar procedure to $\left.3 .[\alpha]_{\mathrm{D}}{ }^{30}+102^{\circ}(c) 1.0, \mathrm{CHCl}_{3}\right) ;{ }^{1} \mathrm{H}$ NMR $(300 \mathrm{MHz}$, $\left.\mathrm{CDCl}_{3}\right) \delta 9.04(\mathrm{~d}, J=9.1 \mathrm{~Hz}, 1 \mathrm{H}), 8.25-8.33(\mathrm{~m}, 1 \mathrm{H}), 7.37-7.60(\mathrm{~m}, 3 \mathrm{H}), 5.35$ (d, $J=5.5 \mathrm{~Hz}, 1 \mathrm{H}), 5.30($ br s, $1 \mathrm{H}), 4.21-4.44(\mathrm{~m}, 5 \mathrm{H}), 3.66-3.75(\mathrm{~m}, 1 \mathrm{H})$, 3.51-3.64 (m, 2H), 3.30-3.43 (m, 1H), 3.29-3.39 (m, 1H), 3.09 (dd, $J=10.2$, $4.7 \mathrm{~Hz}, 1 \mathrm{H}), 2.39(\mathrm{~s}, 3 \mathrm{H}), 2.16(\mathrm{~s}, 3 \mathrm{H}), 2.02-2.13(\mathrm{~m}, 2 \mathrm{H}), 185-2.00(\mathrm{~m}, 2 \mathrm{H})$, $1.54(\mathrm{~d}, J=6.9 \mathrm{~Hz}, 3 \mathrm{H}), 1.19-1.42(\mathrm{~m}, 4 \mathrm{H})$ and $0.85-0.98(\mathrm{~m}, 3 \mathrm{H})$; MS (FAB) $\mathrm{m} / z 617(\mathrm{M}+\mathrm{H})^{+}$; HRMS (ESI) $\mathrm{m} / z$ calcd for $\mathrm{C}_{26} \mathrm{H}_{38} \mathrm{ClN}_{4} \mathrm{O}_{5} \mathrm{~S}_{3} 617.1687$, found $617.1691(\mathrm{M}+\mathrm{H})^{+}$. 


\section{(7S)-7-Deoxy 7-[5-(o-tolyl)-1,3,4-thiadiazol-2-ylthio]lincomycin} (18)

Reaction of 2 (240 mg, $0.39 \mathrm{mmol})$ with 5-(o-tolyl)-1,3,4-thiadiazole-2-thiol $(150 \mathrm{mg}, 0.72 \mathrm{mmol}$ ) gave $\mathbf{1 8}$ as a colorless solid in $22 \%$ yield by a similar procedure to $3 .[\alpha]_{\mathrm{D}}{ }^{31}+88^{\circ}\left(c 1.0, \mathrm{CHCl}_{3}\right) ;{ }^{1} \mathrm{H} \mathrm{NMR}\left(400 \mathrm{MHz}, \mathrm{CDCl}_{3}\right) \delta 9.20$ $(\mathrm{d}, J=9.1 \mathrm{~Hz}, 1 \mathrm{H}), 7.64(\mathrm{~d}, J=7.9 \mathrm{~Hz}, 1 \mathrm{H}), 7.28-7.44(\mathrm{~m}, 3 \mathrm{H}), 5.40(\mathrm{br} \mathrm{s}, 1 \mathrm{H})$, $5.36(\mathrm{~d}, J=5.5 \mathrm{~Hz}, 1 \mathrm{H}), 4.41-4.47(\mathrm{~m}, 1 \mathrm{H}), 4.32(\mathrm{qd}, J=7.1,3.4 \mathrm{~Hz}, 1 \mathrm{H}), 4.27$ (d, $J=10.3 \mathrm{~Hz}, 1 \mathrm{H}), 4.13-4.18(\mathrm{~m}, 1 \mathrm{H}), 3.70-3.75(\mathrm{~m}, 1 \mathrm{H}), 3.59$ (dd, $J=10.1$, $3.5 \mathrm{~Hz}, 1 \mathrm{H}), 3.39$ (dd, $J=7.9,5.4 \mathrm{~Hz}, 1 \mathrm{H}), 3.11(\mathrm{dd}, J=10.5,4.5 \mathrm{~Hz}, 1 \mathrm{H}), 2.61$ (s, 3H), 2.41 (s, 1H), $2.19(\mathrm{~s}, 3 \mathrm{H}), 2.06-2.17(\mathrm{~m}, 3 \mathrm{H}), 1.86-2.03(\mathrm{~m}, 2 \mathrm{H}), 1.57$ (d, $J=7.1 \mathrm{~Hz}, 3 \mathrm{H}), 1.29-1.37(\mathrm{~m}, 4 \mathrm{H})$ and $0.85-0.96(\mathrm{~m}, 3 \mathrm{H})$; MS (FAB) $\mathrm{m} / \mathrm{z}$ $597(\mathrm{M}+\mathrm{H})^{+}$; HRMS (ESI) $\mathrm{m} / z$ calcd for $\mathrm{C}_{27} \mathrm{H}_{41} \mathrm{~N}_{4} \mathrm{O}_{5} \mathrm{~S}_{3}$ 597.2234, found $597.2238(\mathrm{M}+\mathrm{H})^{+}$.

\section{(7S)-7-Deoxy-7-[5-(2-methoxyphenyl)-1,3,4-thiadiazol-2-ylthio] lincomycin (19)}

Reaction of 2 (240 mg, $0.39 \mathrm{mmol})$ with 5-(2-methoxyphenyl)-1,3,4-thiadiazole-2-thiol (130 mg, $0.58 \mathrm{mmol}$ ) gave 19 as a colorless solid in $48 \%$ yield by a similar procedure to $\left.3 .[\alpha]_{\mathrm{D}}{ }^{30}+114^{\circ}(c) 1.2, \mathrm{CHCl}_{3}\right) ;{ }^{1} \mathrm{H} \mathrm{NMR}(400 \mathrm{MHz}$, $\left.\mathrm{CD}_{3} \mathrm{OD}\right) \delta 8.31(\mathrm{dd}, J=8.0,1.6 \mathrm{~Hz}, 1 \mathrm{H}), 7.55(\mathrm{ddd}, J=8.0,7.0,1.6 \mathrm{~Hz}, 1 \mathrm{H})$, $7.24(\mathrm{~d}, J=8.0 \mathrm{~Hz}, 1 \mathrm{H}), 7.10-7.18(\mathrm{~m}, 1 \mathrm{H}), 5.27(\mathrm{~d}, J=5.7 \mathrm{~Hz}, 1 \mathrm{H}), 4.57$ (dd, $J=9.7,3.2 \mathrm{~Hz}, 1 \mathrm{H}), 4.43(\mathrm{~d}, J=9.7 \mathrm{~Hz}, 1 \mathrm{H}), 4.34(\mathrm{qd}, J=7.0,3.1 \mathrm{~Hz}, 1 \mathrm{H})$, $4.06-4.16(\mathrm{~m}, 1 \mathrm{H}), 4.04(\mathrm{~s}, 3 \mathrm{H}), 3.80-3.83(\mathrm{~m}, 1 \mathrm{H}), 3.58(\mathrm{dd}, J=10.3,3.2 \mathrm{~Hz}$, $1 \mathrm{H}), 3.26(\mathrm{dd}, J=8.6,6.0 \mathrm{~Hz}, 1 \mathrm{H}), 2.99(\mathrm{dd}, J=10.4,5.0 \mathrm{~Hz}, 1 \mathrm{H}), 2.35(\mathrm{~s}, 3 \mathrm{H})$, 2.15-2.26 (m, 1H), 2.02-2.14 (m, 2H), $2.01(\mathrm{~s}, 3 \mathrm{H}), 1.96-2.00(\mathrm{~m}, 1 \mathrm{H})$, $1.71-1.91(\mathrm{~m}, 1 \mathrm{H}), 1.54(\mathrm{~d}, J=7.0 \mathrm{~Hz}, 3 \mathrm{H}), 1.27-1.41(\mathrm{~m}, 4 \mathrm{H})$ and $0.86-0.95$ $(\mathrm{m}, 3 \mathrm{H})$; $\mathrm{MS}(\mathrm{FAB}) \mathrm{m} / \mathrm{z} 613(\mathrm{M}+\mathrm{H})^{+}$; HRMS (ESI) $\mathrm{m} / \mathrm{z}$ calcd for $\mathrm{C}_{27} \mathrm{H}_{41} \mathrm{~N}_{4} \mathrm{O}_{6} \mathrm{~S}_{3}$ 613.2183, found $613.2174(\mathrm{M}+\mathrm{H})^{+}$.

\section{(7S)-7-Deoxy-7-\{5-[2-(methylthio)phenyl]-1,3,4-thiadiazol-2-ylthio $\}$ lincomycin (20)}

Reaction of 2 (240 mg, $0.39 \mathrm{mmol})$ with 5-[2-(methylthio)phenyl]-1,3, 4-thiadiazole-2-thiol ( $150 \mathrm{mg}, 0.62 \mathrm{mmol}$ ) gave 20 as a colorless solid in $44 \%$ yield by a similar procedure to $3 .[\alpha]_{\mathrm{D}}{ }^{30}+141^{\circ}\left(c 1.1, \mathrm{CHCl}_{3}\right) ;{ }^{1} \mathrm{H}$ NMR $\left(400 \mathrm{MHz}, \mathrm{CDCl}_{3}\right) \delta 9.13(\mathrm{~d}, J=8.8 \mathrm{~Hz}, 1 \mathrm{H}), 8.00-8.06(\mathrm{~m}, 1 \mathrm{H}), 7.42-7.54$ $(\mathrm{m}, 2 \mathrm{H}), 7.29-7.37(\mathrm{~m}, 1 \mathrm{H}), 5.35(\mathrm{~d}, J=5.5 \mathrm{~Hz}, 1 \mathrm{H}), 4.37-4.47(\mathrm{~m}, 1 \mathrm{H})$, $4.22-4.35(\mathrm{~m}, 2 \mathrm{H}), \quad 4.07-4.22(\mathrm{~m}, 2 \mathrm{H}), 3.72(\mathrm{t}, J=3.3 \mathrm{~Hz}, 1 \mathrm{H}), \quad 3.57$ $(\mathrm{td}, J=10.0,3.3 \mathrm{~Hz}, 1 \mathrm{H}), 3.41(\mathrm{dd}, J=7.9,5.4 \mathrm{~Hz}, 1 \mathrm{H}), 3.09(\mathrm{dd}, J=10.6$, $4.6 \mathrm{~Hz}, 1 \mathrm{H}), 2.50(\mathrm{~s}, 3 \mathrm{H}), 2.18(\mathrm{~s}, 3 \mathrm{H}), 2.04-2.16(\mathrm{~m}, 2 \mathrm{H}), 1.89-2.01(\mathrm{~m}, 3 \mathrm{H})$, $1.55(\mathrm{~d}, J=7.1 \mathrm{~Hz}, 1 \mathrm{H}), 1.25-1.39(\mathrm{~m}, 4 \mathrm{H})$ and $0.84-0.97(\mathrm{~m}, 3 \mathrm{H})$; MS (FAB) $\mathrm{m} / \mathrm{z} 629(\mathrm{M}+\mathrm{H})^{+}$; HRMS (ESI) $\mathrm{m} / z$ calcd for $\mathrm{C}_{27} \mathrm{H}_{41} \mathrm{~N}_{4} \mathrm{O}_{5} \mathrm{~S}_{4} 629.1954$, found $629.1960(\mathrm{M}+\mathrm{H})^{+}$.

\section{(7S)-7-Deoxy-7-\{5-[2-(methylsulfonyl)phenyl]-1,3,4-thiadiazol-2- ylthio\}lincomycin (21)}

Reaction of $2(240 \mathrm{mg}, 0.39 \mathrm{mmol})$ with 5-[2-(methylsulfonyl)phenyl]-1,3, 4-thiadiazole-2-thiol (120 mg, $0.44 \mathrm{mmol}$ ) gave 21 as a colorless solid in $32 \%$ yield by a similar procedure to $3 .[\alpha]_{\mathrm{D}}{ }^{30}+73^{\circ}\left(\mathrm{c} \mathrm{1.1}, \mathrm{CHCl}_{3}\right) ;{ }^{1} \mathrm{H}$ NMR $\left(400 \mathrm{MHz}, \mathrm{CD}_{3} \mathrm{OD}\right) \delta 8.22-8.26(\mathrm{~m}, 1 \mathrm{H}), 7.82-7.87(\mathrm{~m}, 2 \mathrm{H}), 7.69-7.73$ $(\mathrm{m}, 1 \mathrm{H}), 5.28(\mathrm{~d}, J=5.6 \mathrm{~Hz}, 1 \mathrm{H}), 4.63(\mathrm{dd}, J=9.8,3.1 \mathrm{~Hz}, 1 \mathrm{H}), 4.51$ $(\mathrm{qd}, J=6.9,2.9 \mathrm{~Hz}, 1 \mathrm{H}), 4.45(\mathrm{~d}, J=9.8 \mathrm{~Hz}, 1 \mathrm{H}), 4.12(\mathrm{dd}, J=10.3$, $5.6 \mathrm{~Hz}, 1 \mathrm{H}), 3.80-3.84(\mathrm{~m}, 1 \mathrm{H}), 3.56-3.64(\mathrm{~m}, 2 \mathrm{H}), 3.34-3.39(\mathrm{~m}, 2 \mathrm{H})$, $3.25(\mathrm{dd}, J=8.5,6.2 \mathrm{~Hz}, 1 \mathrm{H}), 3.00(\mathrm{dd}, J=10.4,5.1 \mathrm{~Hz}, 1 \mathrm{H}), 2.40(\mathrm{~s}, 3 \mathrm{H})$, 2.16-2.27 (m, 1H), 2.02-2.10 (m, 3H), $2.02(\mathrm{~s}, 3 \mathrm{H}), 1.80-1.90(\mathrm{~m}, 1 \mathrm{H}), 1.59$ $(\mathrm{d}, J=6.9 \mathrm{~Hz}, 3 \mathrm{H}), 1.28-1.39(\mathrm{~m}, 4 \mathrm{H})$ and $0.89-0.95(\mathrm{~m}, 3 \mathrm{H})$; MS (FAB) $\mathrm{m} / \mathrm{z}$ $661(\mathrm{M}+\mathrm{H})^{+}$; HRMS (ESI) $\mathrm{m} / z$ calcd for $\mathrm{C}_{27} \mathrm{H}_{41} \mathrm{~N}_{4} \mathrm{O}_{7} \mathrm{~S}_{4}$ 661.1853, found $661.1843(\mathrm{M}+\mathrm{H})^{+}$.

\section{(7S)-7-[5-(2-Cyanophenyl)-1,3,4-thiadiazol-2-ylthio]-7- \\ deoxylincomycin (22)}

Reaction of 2 (240 mg, $0.39 \mathrm{mmol})$ with 2-(5-mercapto-1,3,4-thiadiazol-2-yl) benzonitrile ( $100 \mathrm{mg}, 0.46 \mathrm{mmol}$ ) gave 22 as a colorless solid in $32 \%$ yield by a similar procedure to $3 . \mathrm{mp} 223-229^{\circ} \mathrm{C}$ (decomp.); $[\alpha]_{\mathrm{D}}{ }^{30}-64^{\circ}\left(c 1.5, \mathrm{CHCl}_{3}\right)$; IR (KBr) 3397, 2922, 2227, 1655 and $1510 \mathrm{~cm}^{-1} ;{ }^{1} \mathrm{H}$ NMR (300 MHz, $\left.\mathrm{CDCl}_{3}\right)$ $\delta 9.05(\mathrm{~d}, J=8.8 \mathrm{~Hz}, 1 \mathrm{H}), 8.04(\mathrm{~d}, J=7.7 \mathrm{~Hz}, 1 \mathrm{H}), 7.75-7.82(\mathrm{~m}, 1 \mathrm{H}), 7.68$ (td, $J=7.8,1.4 \mathrm{~Hz}, 1 \mathrm{H}), 7.52-7.60$ (m, 1H), 5.27 (d, $J=5.8 \mathrm{~Hz}, 1 \mathrm{H}), 4.22-4.44$ $(\mathrm{m}, 2 \mathrm{H}), 4.15(\mathrm{~d}, J=9.6 \mathrm{~Hz}, 1 \mathrm{H}), 4.07(\mathrm{dd}, J=9.9,5.5 \mathrm{~Hz}, 1 \mathrm{H}), 3.61-3.68$ $(\mathrm{m}, 1 \mathrm{H}), 3.44-3.56(\mathrm{~m}, 1 \mathrm{H}), 3.31-3.39(\mathrm{~m}, 1 \mathrm{H}), 2.99-3.09(\mathrm{~m}, 1 \mathrm{H}), 2.36-2.47$ $(\mathrm{m}, 3 \mathrm{H}), 2.25-2.36(\mathrm{~m}, 1 \mathrm{H}), 2.11(\mathrm{~s}, 3 \mathrm{H}), 1.80-2.09(\mathrm{~m}, 4 \mathrm{H}), 1.43-1.58$ $(\mathrm{m}, 3 \mathrm{H})$ and $1.16-1.31(\mathrm{~m}, 5 \mathrm{H}) ;{ }^{13} \mathrm{C} \mathrm{NMR}\left(100 \mathrm{MHz}, \mathrm{CDCl}_{3}\right) \delta 185.8,177.7$, $153.9,134.7,133.3,131.6,131.1,129.6,117.1,110.7,90.9,70.9,70.3,69.2,68.5$, 67.9, 63.0, 54.4, 51.4, 42.1, 37.7, 37.6, 35.8, 21.6, 15.8, 15.2 and 14.2; MS (FAB) $\mathrm{m} / \mathrm{z} 608(\mathrm{M}+\mathrm{H})^{+}$; HRMS (ESI) $\mathrm{m} / \mathrm{z}$ calcd for $\mathrm{C}_{27} \mathrm{H}_{38} \mathrm{~N}_{5} \mathrm{O}_{5} \mathrm{~S}_{3} 608.2030$, found $608.2033(\mathrm{M}+\mathrm{H})^{+}$.

\section{(7S)-7-[5-(2-Aminopyridin-3-yl)-1,3,4-thiadiazol-2-ylthio]-7- deoxylincomycin (24)}

To a solution of $23^{10-12}(200 \mathrm{mg}, 0.29 \mathrm{mmol})$ and $\mathrm{K}_{2} \mathrm{CO}_{3}(118 \mathrm{mg}, 0.85 \mathrm{mmol})$ in $\mathrm{N}, \mathrm{N}$-dimethylformamide (DMF) $(2.0 \mathrm{ml})$ was added 5-(2-aminopyridin-3yl)-1,3,4-thiadiazole-2-thiol ( $120 \mathrm{mg}, 0.57 \mathrm{mmol})$ and the mixture was stirred at $80^{\circ} \mathrm{C}$ for $10 \mathrm{~h}$. After cooled to room temperature, the mixture was diluted with ethyl acetate and washed with brine. The organic phase was dried over $\mathrm{Na}_{2} \mathrm{SO}_{4}$, filtered and concentrated in vacuo. The residue was purified by silica gel column chromatography (hexane-ethyl acetate) to give a colorless solid $(54 \mathrm{mg})$. To a solution of the compound obtained above $(54 \mathrm{mg})$ in $\mathrm{MeOH}$ $(1 \mathrm{ml})$ was added $1 \mathrm{~N} \mathrm{HCl}(1 \mathrm{ml})$ and the reaction mixture was stirred at room temperature for $10 \mathrm{~min}$. The mixture was diluted with ethyl acetate and extracted with $\mathrm{H}_{2} \mathrm{O}$. The aqueous phase was neutralized with $10 \%$ aqueous $\mathrm{NaHCO}_{3}$ and extracted with ethyl acetate. The organic phase was dried over $\mathrm{Na}_{2} \mathrm{SO}_{4}$, filtered and concentrated in vacuo. The resulting residue was purified by preparative thin-layer chromatography $\left(\mathrm{CHCl}_{3} / \mathrm{CH}_{3} \mathrm{OH} / 28 \%\right.$ aq $\left.\mathrm{NH}_{4} \mathrm{OH}=10 / 1 / 0.1\right)$ to afford $24(16 \mathrm{mg}, 9 \%)$ as colorless solid. $[\alpha]_{\mathrm{D}}{ }^{30}+84^{\circ}$ (c 0.22, $\left.\mathrm{CHCl}_{3}\right) ;{ }^{1} \mathrm{H} \mathrm{NMR}\left(300 \mathrm{MHz}, \mathrm{CD}_{3} \mathrm{OD}\right) \delta 8.10(\mathrm{dd}, J=4.9,1.7 \mathrm{~Hz}, 1 \mathrm{H})$, $7.87(\mathrm{dd}, J=7.8,1.7 \mathrm{~Hz}, 1 \mathrm{H}), 6.75(\mathrm{dd}, J=7.8,4.9 \mathrm{~Hz}, 1 \mathrm{H}), 5.27(\mathrm{~d}, J=5.6 \mathrm{~Hz}$, $1 \mathrm{H}), 4.58-4.63(\mathrm{~m}, 2 \mathrm{H}), 4.12(\mathrm{dd}, J=10.2,5.6 \mathrm{~Hz}, 1 \mathrm{H}), 3.81-3.83(\mathrm{~m}, 1 \mathrm{H})$, $3.55-3.60(\mathrm{~m}, 1 \mathrm{H}), 3.20-3.28(\mathrm{~m}, 1 \mathrm{H}), 3.01(\mathrm{dd}, J=10.4,5.0 \mathrm{~Hz}, 1 \mathrm{H}), 2.37$ (s, $3 \mathrm{H}), 2.14-2.25(\mathrm{~m}, 1 \mathrm{H}), 2.02-2.10(\mathrm{~m}, 1 \mathrm{H}), 2.01(\mathrm{~s}, 3 \mathrm{H}), 1.79-1.89(\mathrm{~m}, 1 \mathrm{H})$, $1.57(\mathrm{~d}, J=6.8 \mathrm{~Hz}, 3 \mathrm{H}), 1.27-1.37(\mathrm{~m}, 4 \mathrm{H})$ and $0.86-0.94(\mathrm{~m}, 3 \mathrm{H})$; MS (FAB) $\mathrm{m} / z 599(\mathrm{M}+\mathrm{H})^{+}$; HRMS (ESI) $\mathrm{m} / z$ calcd for $\mathrm{C}_{25} \mathrm{H}_{39} \mathrm{~N}_{6} \mathrm{O}_{5} \mathrm{~S}_{3} 599.2139$, found $599.2152(\mathrm{M}+\mathrm{H})^{+}$.

(7S)-7-Deoxy-7-\{5-[2-(methoxycarbonyl)phenyl]-1,3,4-thiadiazol-2ylthio\}lincomycin (26)

To a solution of $25^{11}(80 \mathrm{mg}, 0.19 \mathrm{mmol})$ in DMF $(0.5 \mathrm{ml})$ were added $1 \mathrm{M}$ sodium hexamethyldisilazane tetrahydrofuran solution $(0.38 \mathrm{ml}, 0.38 \mathrm{mmol})$ and methyl 2-(5-chloro-1,3,4-thiadiazol-2-yl)benzoate (53 mg, $0.21 \mathrm{mmol})$ and the mixture was stirred at room temperature for $10 \mathrm{~min}$. The mixture was diluted with ethyl acetate and washed with water. The organic phase was dried over $\mathrm{Na}_{2} \mathrm{SO}_{4}$, filtered and concentrated in vacuo. The residue was purified by silica gel column chromatography $\left(\mathrm{CHCl}_{3}-\mathrm{MeOH}\right)$ to give a colorless solid (93 mg). ${ }^{1} \mathrm{H}$ NMR (400 MHz, $\left.\mathrm{CDCl}_{3}\right) \delta 9.00(\mathrm{~d}, J=9.0 \mathrm{~Hz}, 1 \mathrm{H}), 7.90-7.96$ $(\mathrm{m}, 1 \mathrm{H}), 7.55-7.68(\mathrm{~m}, 3 \mathrm{H}), 5.36(\mathrm{~d}, J=5.6 \mathrm{~Hz}, 1 \mathrm{H}), 5.31$ (br s, $1 \mathrm{H}), 4.30-4.46$ $(\mathrm{m}, 2 \mathrm{H}), 4.27(\mathrm{~d}, J=10.2 \mathrm{~Hz}, 1 \mathrm{H}), 4.16(\mathrm{dd}, J=10.2,5.5 \mathrm{~Hz}, 1 \mathrm{H}), 3.77-3.84$ (m, 3H), 3.68-3.75 (m, $2 \mathrm{H}), 3.59(\mathrm{dd}, J=10.0,3.2 \mathrm{~Hz}, 1 \mathrm{H}), 3.48(\mathrm{~s}, 1 \mathrm{H}), 3.35$ (dd, $J=7.9,5.5 \mathrm{~Hz}, 1 \mathrm{H}), 3.09$ (dd, $J=10.6,4.5 \mathrm{~Hz}, 1 \mathrm{H}), 2.37$ (s, 3H), 2.15-2.22 $(\mathrm{m}, 3 \mathrm{H}), 1.83-2.13(\mathrm{~m}, 5 \mathrm{H}), 1.55(\mathrm{~d}, J=6.8 \mathrm{~Hz}, 3 \mathrm{H}), 1.29-1.36(\mathrm{~m}, 3 \mathrm{H})$ and 0.85-0.93 (m, 3H); MS (FAB) $m / z 641(\mathrm{M}+\mathrm{H})^{+}$.

\section{(7S)-7-Deoxy-7-[5-(2-dimethylcarbamoylphenyl)-1,3,4-thiadiazol- 2-ylthio]lincomycin (28)}

To a solution of $26(268 \mathrm{mg}, 0.42 \mathrm{mmol})$ in $\mathrm{MeOH}(3.0 \mathrm{ml})$ were added $2 \mathrm{~N} \mathrm{NaOH}(2.0 \mathrm{ml})$ and the mixture was stirred at room temperature for $30 \mathrm{~min}$. The mixture was concentrated in vacuo and acidified with $1 \mathrm{~N} \mathrm{HCl}$ and extracted with $\mathrm{CHCl}_{3}$. The organic phase was dried over $\mathrm{Na}_{2} \mathrm{SO}_{4}$, filtered and concentrated in vacuo to give a carboxylic acid $(150 \mathrm{mg})$. To a solution of the compound obtained above $(60 \mathrm{mg}, 0.096 \mathrm{mmol})$ in DMF $(0.30 \mathrm{ml})$ were added hydroxybenzotriazole $(16 \mathrm{mg}, 0.12 \mathrm{mmol})$ and 1-(3-dimethylaminopropyl)3-ethylcarbodiimide hydrochloride ( $22 \mathrm{mg}, 0.12 \mathrm{mmol}$ ) and $2 \mathrm{~m}$ dimethylamine $\mathrm{MeOH}$ solution $(96 \mu \mathrm{l}, 0.19 \mathrm{mmol})$ and stirred at room temperature for $2 \mathrm{~h}$. The mixture was diluted with ethyl acetate and washed with $10 \%$ aqueous $\mathrm{NaHCO}_{3}$ to afford $28(52 \mathrm{mg}, 43 \%)$ as colorless solid. $[\alpha]_{D}{ }^{30}+131^{\circ}(c 1.2$, 
$\left.\mathrm{CHCl}_{3}\right) ;{ }^{1} \mathrm{H}$ NMR $\left(300 \mathrm{MHz}, \mathrm{CDCl}_{3}\right) \delta 8.92(\mathrm{~d}, J=9.1 \mathrm{~Hz}, 1 \mathrm{H}), 7.88-7.93$ (m, 1H), 7.49-7.58 (m, 2H), 7.36-7.40 (m, 1H), $5.34(\mathrm{~d}, J=5.4 \mathrm{~Hz}, 1 \mathrm{H}), 5.30$ $(\mathrm{d}, J=3.4 \mathrm{~Hz}, 1 \mathrm{H}), 4.34-4.44(\mathrm{~m}, 2 \mathrm{H}), 4.23(\mathrm{~d}, J=10.0 \mathrm{~Hz}, 1 \mathrm{H}), 4.10-4.16$ $(\mathrm{m}, 1 \mathrm{H}), 3.69-3.72(\mathrm{~m}, 1 \mathrm{H}), 3.53-3.60(\mathrm{~m}, 1 \mathrm{H}), 3.34-3.39(\mathrm{~m}, 1 \mathrm{H}), 3.12$ (s, 3H), 3.07-3.11 (m, 1H), $2.83(\mathrm{~s}, 3 \mathrm{H}), 2.70-2.77(\mathrm{~m}, 1 \mathrm{H}), 2.41(\mathrm{~s}, 3 \mathrm{H})$ 2.15-2.20 (m, 3H), 2.06-2.14 (m, 2H), 1.87-2.01 (m, $2 \mathrm{H}), 1.53(\mathrm{~d}, J=6.8 \mathrm{~Hz}$, $3 \mathrm{H}), 1.29-1.38(\mathrm{~m}, 4 \mathrm{H})$ and $0.86-0.93(\mathrm{~m}, 3 \mathrm{H})$; MS (FAB) $\mathrm{m} / \mathrm{z} 654(\mathrm{M}+\mathrm{H})^{+}$; HRMS (ESI) $\mathrm{m} / z$ calcd for $\mathrm{C}_{29} \mathrm{H}_{44} \mathrm{~N}_{5} \mathrm{O}_{6} \mathrm{~S}_{3} 654.2448$, found $654.2456(\mathrm{M}+\mathrm{H})^{+}$.

\section{(7S)-7-[5-(2-Carbamoylphenyl)-1,3,4-thiadiazol-2-ylthio]-7-} deoxylincomycin (27)

Reaction of the carboxylic acid obtained in the first step of 28 (46 mg, $0.073 \mathrm{mmol})$ with $7 \mathrm{~N} \mathrm{NH}_{3} \mathrm{MeOH}$ solution $(0.020 \mathrm{ml}, 0.14 \mathrm{mmol})$ gave 27 as a colorless solid in $44 \%$ yield by a similar procedure to $28 . \mathrm{mp} 228-235^{\circ} \mathrm{C}$ (decomp.); $[\alpha]_{\mathrm{D}}{ }^{30}+127^{\circ}\left(c\right.$ 1.1, $\left.\mathrm{CHCl}_{3}\right) ; \mathrm{IR}$ (KBr) 3397, 2924, 1664 and $1510 \mathrm{~cm}^{-1} ;{ }^{1} \mathrm{H}$ NMR $\left(300 \mathrm{MHz}, \mathrm{CD}_{3} \mathrm{OD}\right) \delta 7.76-7.83(\mathrm{~m}, 1 \mathrm{H}), 7.57-7.67$ $(\mathrm{m}, 3 \mathrm{H}), 5.27(\mathrm{~d}, J=5.6 \mathrm{~Hz}, 1 \mathrm{H}), 4.60(\mathrm{dd}, J=9.7,3.2 \mathrm{~Hz}, 1 \mathrm{H}), 4.37-4.47$ $(\mathrm{m}, 2 \mathrm{H}), 4.11(\mathrm{dd}, J=10.2,5.6 \mathrm{~Hz}, 1 \mathrm{H}), 3.81(\mathrm{~d}, J=2.2 \mathrm{~Hz}, 1 \mathrm{H}), 3.55-3.60$ (m, 2H), 3.27 (dd, $J=8.6,6.2 \mathrm{~Hz}, 1 \mathrm{H}), 3.53-3.63(\mathrm{~m}, 1 \mathrm{H}), 2.34-2.42(\mathrm{~m}, 3 \mathrm{H})$, 2.01-2.08 (m, 2H), $2.00(\mathrm{~s}, 3 \mathrm{H}), 1.79-1.90(\mathrm{~m}, 1 \mathrm{H}), 1.56(\mathrm{~d}, J=6.8 \mathrm{~Hz}, 3 \mathrm{H})$, $1.26-1.40(\mathrm{~m}, 4 \mathrm{H})$ and $0.86-0.97(\mathrm{~m}, 3 \mathrm{H}) ;{ }^{13} \mathrm{C} \mathrm{NMR}\left(100 \mathrm{MHz}, \mathrm{CDCl}_{3}\right) \delta$ $178.8,170.2,166.8,164.4,135.7,130.9,130.8,130.7,128.3,127.3,89.0,71.6$, 71.1, 69.3, 68.4, 68.3, 62.6, 53.1, 44.7, 41.8, 38.1, 38.0, 35.7, 21.6, 18.9, 14.7 and 14.3; MS (FAB) $m / z 626(\mathrm{M}+\mathrm{H})^{+}$; HRMS (ESI) $\mathrm{m} / z$ calcd for $\mathrm{C}_{27} \mathrm{H}_{40} \mathrm{~N}_{5} \mathrm{O}_{6} \mathrm{~S}_{3}$ 626.2135, found $626.2137(\mathrm{M}+\mathrm{H})^{+}$

\section{(7S)-7-[5-(2-Aminophenyl)-1,3,4-thiadiazol-2-ylthio]-7-} deoxylincomycin (29)

To a solution of compound $9(390 \mathrm{mg}, 0.63 \mathrm{mmol})$ in ethanol $(12.0 \mathrm{ml})$ was added $\mathrm{SnCl}_{2} \cdot \mathrm{H}_{2} \mathrm{O}(560 \mathrm{mg}, 2.5 \mathrm{mmol}), \mathrm{NaBH}_{4}(16.0 \mathrm{mg}, 0.42 \mathrm{mmol})$ and stirred at room temperature for $2 \mathrm{~h}$. The mixture was concentrated under reduced pressure. The resulting residue was dissolved by ethyl acetate, washed with water, dried over $\mathrm{MgSO}_{4}$ and concentrated in vacuo. The resulting residue was purified by preparative thin-layer chromatography $\left(\mathrm{CHCl}_{3} / \mathrm{CH}_{3} \mathrm{OH} / 28 \%\right.$ aq $\left.\mathrm{NH}_{4} \mathrm{OH}=20 / 1 / 0.1\right)$ to obtain the title compound as a colorless solid (123 mg, 33\%). $[\alpha]_{\mathrm{D}}{ }^{31}+62^{\circ}\left(c 1.3, \mathrm{CHCl}_{3}\right) ;{ }^{1} \mathrm{H}$ NMR $\left(400 \mathrm{MHz}, \mathrm{CDCl}_{3}\right) \delta 8.94$ $(\mathrm{d}, J=9.3 \mathrm{~Hz}, 1 \mathrm{H}), 7.37(\mathrm{dd} J=7.9,1.4 \mathrm{~Hz}, 1 \mathrm{H}), 7.21-7.26(\mathrm{~m}, 1 \mathrm{H}), 6.81$ $(\mathrm{d}, J=8.1 \mathrm{~Hz}, 1 \mathrm{H}), 6.74(\mathrm{t}, J=7.3 \mathrm{~Hz}, 1 \mathrm{H}), 6.10($ br s, $2 \mathrm{H}), 5.36(\mathrm{~d}, J=5.6 \mathrm{~Hz}$, $1 \mathrm{H}), 5.28-5.35(\mathrm{~m}, 1 \mathrm{H}), 4.23-4.33(\mathrm{~m}, 2 \mathrm{H}), 4.12-4.18(\mathrm{~m}, 1 \mathrm{H}), 3.68-3.75$ (m, $1 \mathrm{H}), 3.53-3.13(\mathrm{~m}, 1 \mathrm{H}), 3.31(\mathrm{dd}, J=8.0,5.7 \mathrm{~Hz}, 1 \mathrm{H}), 3.09$ (dd, $J=10.5$, $4.7 \mathrm{~Hz}, 1 \mathrm{H}), 2.72-2.81(\mathrm{~m}, 1 \mathrm{H}), 2.39(\mathrm{~s}, 3 \mathrm{H}), 2.18(\mathrm{~s}, 3 \mathrm{H}), 2.04-2.16(\mathrm{~m}, 2 \mathrm{H})$, $1.87-2.02(\mathrm{~m}, 3 \mathrm{H}), 1.55(\mathrm{~d}, J=7.1 \mathrm{~Hz}, 3 \mathrm{H}), 1.25-1.38(\mathrm{~m}, 5 \mathrm{H})$ and $0.87-0.96$ $(\mathrm{m}, 3 \mathrm{H})$; MS (FAB) $\mathrm{m} / \mathrm{z} 598(\mathrm{M}+\mathrm{H})^{+}$; HRMS (ESI) $\mathrm{m} / \mathrm{z}$ calcd for $\mathrm{C}_{26} \mathrm{H}_{40} \mathrm{~N}_{5} \mathrm{O}_{5} \mathrm{~S}_{3}$ 598.2186, found $598.2185(\mathrm{M}+\mathrm{H})^{+}$.

\section{(7S)-7-[5-(3-Aminophenyl)-1,3,4-thiadiazol-2-ylthio]-7-}

\section{deoxylincomycin (30)}

Compound 30 was obtained from compound $10(75 \mathrm{mg}, 0.13 \mathrm{mmol})$ as a colorless solid in $24 \%$ yield by a similar procedure to 29 . $[\alpha]_{\mathrm{D}}{ }^{30}+140^{\circ}(c$ c 1.2 , $\left.\mathrm{CHCl}_{3}\right) ;{ }^{1} \mathrm{H} \mathrm{NMR}\left(300 \mathrm{MHz}, \mathrm{CDCl}_{3}\right) \delta 8.94(\mathrm{~d}, J=9.1 \mathrm{~Hz}, 1 \mathrm{H}), 7.37$ $(\mathrm{d}, J=8.1 \mathrm{~Hz}, 1 \mathrm{H}), 7.20-7.26(\mathrm{~m}, 1 \mathrm{H}), 6.80(\mathrm{~d}, J=8.1 \mathrm{~Hz}, 1 \mathrm{H}), 6.73$ (t, $J=7.6 \mathrm{~Hz}, 1 \mathrm{H}), 6.11$ (br s, $2 \mathrm{H}), 5.35$ (d, $J=5.5 \mathrm{~Hz}, 1 \mathrm{H}), 5.32$ (br s, $1 \mathrm{H})$, $4.37-4.49(\mathrm{~m}, 1 \mathrm{H}), 4.23-4.35(\mathrm{~m}, 2 \mathrm{H}), 4.15(\mathrm{dd}, J=10.0,5.3 \mathrm{~Hz}, 1 \mathrm{H}), 3.71$ (d, $J=2.5 \mathrm{~Hz}, 1 \mathrm{H}), 3.58(\mathrm{dd}, J=10.0,3.6 \mathrm{~Hz}, 1 \mathrm{H}), 3.31(\mathrm{dd}, J=7.4,5.3 \mathrm{~Hz}$, $1 \mathrm{H}), 3.09(\mathrm{dd}, J=10.2,4.9 \mathrm{~Hz}, 1 \mathrm{H}), 2.39(\mathrm{~s}, 3 \mathrm{H}), 2.18(\mathrm{~s}, 3 \mathrm{H}), 2.05-2.16$ $(\mathrm{m}, 2 \mathrm{H}), 1.86-2.02(\mathrm{~m}, 3 \mathrm{H}), 1.55(\mathrm{~d}, J=6.9 \mathrm{~Hz}, 3 \mathrm{H}), 1.22-1.40(\mathrm{~m}, 4 \mathrm{H})$ and 0.87-0.97 (m, 3H); MS (FAB) $\mathrm{m} / z 598(\mathrm{M}+\mathrm{H})^{+}$; HRMS (ESI) $\mathrm{m} / \mathrm{z}$ calcd for $\mathrm{C}_{26} \mathrm{H}_{40} \mathrm{~N}_{5} \mathrm{O}_{5} \mathrm{~S}_{3}$ 598.2186, found $598.2192(\mathrm{M}+\mathrm{H})^{+}$.

\section{(7S)-7-[5-(4-Aminophenyl)-1,3,4-thiadiazol-2-ylthio]-7-} deoxylincomycin (31)

Compound 31 was obtained from compound $11(50 \mathrm{mg}, 0.84 \mathrm{mmol})$ as a colorless solid by a similar procedure to $29 .[\alpha]_{D}{ }^{30}+67^{\circ}\left(c 1.1, \mathrm{CHCl}_{3}\right)$; ${ }^{1} \mathrm{H}$ NMR $\left(400 \mathrm{MHz}, \mathrm{CD}_{3} \mathrm{OD}\right) \delta 7.59-7.65(\mathrm{~m}, 2 \mathrm{H}), 6.70-6.75(\mathrm{~m}, 2 \mathrm{H}), 5.26$ $(\mathrm{d}, J=5.6 \mathrm{~Hz}, 1 \mathrm{H}), 4.55(\mathrm{dd}, J=9.8,3.2 \mathrm{~Hz}, 1 \mathrm{H}), 4.42(\mathrm{~d}, J=10.4 \mathrm{~Hz}, 1 \mathrm{H})$ $4.30(\mathrm{qd}, J=6.9,3.2 \mathrm{~Hz}, 1 \mathrm{H}), 4.07-4.15(\mathrm{~m}, 2 \mathrm{H}), 3.79-3.82(\mathrm{~m}, 1 \mathrm{H}), 3.58$ (dd, $J=10.3,3.2 \mathrm{~Hz}, 1 \mathrm{H}$ ), 3.25 (dd, $J=8.2,6.2 \mathrm{~Hz}, 1 \mathrm{H}$ ), 2.98 (dd, $J=10.5$, $5.1 \mathrm{~Hz}, 1 \mathrm{H}), 2.34(\mathrm{~s}, 3 \mathrm{H}), 2.13-2.25(\mathrm{~m}, 1 \mathrm{H}), 2.03(\mathrm{~s}, 3 \mathrm{H}), 1.97-2.02(\mathrm{~m}, 1 \mathrm{H})$, $1.78-1.91(\mathrm{~m}, 1 \mathrm{H}), 1.53(\mathrm{~d}, J=7.0 \mathrm{~Hz}, 3 \mathrm{H}), 1.29-1.39(\mathrm{~m}, 4 \mathrm{H})$ and $0.89-0.95$ $(\mathrm{m}, 3 \mathrm{H})$; MS (FAB) $\mathrm{m} / z 598(\mathrm{M}+\mathrm{H})^{+}$; HRMS (ESI) $\mathrm{m} / z$ calcd for $\mathrm{C}_{26} \mathrm{H}_{40} \mathrm{~N}_{5} \mathrm{O}_{5} \mathrm{~S}_{3}$ 598.2186, found $598.2192(\mathrm{M}+\mathrm{H})^{+}$.

\section{In vitro antibacterial activity}

Minimum inhibitory concentration was determined by the agar dilution method. Test strains were subjected to seed culture using sensitivity test broth (Nissui Pharmaceutical, Tokyo, Japan) cultured on blood agar plate for S. pneumoniae, S. pyogenes and H. influenzae. A $5 \mu \mathrm{l}$ portion of cell suspension of the test strains having about $10^{6}$ colony-forming units per $\mathrm{ml}$ was inoculated into sensitivity disk agar (Nissui Pharmaceutical) supplemented with 5\% horse blood and incubated at $37^{\circ} \mathrm{C}$ for $20 \mathrm{~h}$. Then, minimum inhibitory concentration was defined as the lowest drug concentration that prevented visible growth.

\section{CONFLICT OF INTEREST}

The authors declare no conflict of interest.

\section{ACKNOWLEDGEMENTS}

We thank Dr E Shitara, Mr A Tamura and Dr T Okutomi for valuable scientific discussion. We are grateful to Professor Emeritus Dr M Konno for supervision through our in-house drug discovery program in lincomycin field. We are also grateful to Ms T Miyara, Ms S Miki, Ms K Kaneda, Dr T Murata and Mr S Sato for contribution toward analytical chemistry; Mr K Yamada for biological studies; and Ms M Takagi for manuscript. We also thank Ms M Ishii for direction in intellectual properties.

1 Mason, D. J., Dietz, A. \& Deboer, C. Lincomycin, a new antibiotic I. Discovery and biological properties. Antimicrob. Agents Chemother. 1962, 554-559 (1962).

2 Magerlein, B. J., Birkenmeyer, R. D. \& Kagan, F. Chemical modification of lincomycin. Antimicrob. Agents Chemother. 1966, 727-736 (1966).

3 Schlünzen, F. et al. Structural basis for the interaction of antibiotics with the peptidyl transferase centre in eubacteria. Nature 413, 814-821 (2001).

4 Morimoto, S., Takahashi, Y., Watanabe, Y. \& Omura, S. Chemical modification of erythromycins. I. Synthesis and antibacterial activity of 6-O-methylerythromycins A. J. Antibiot. 37, 187-189 (1984).

5 Djokic, S. et al. Erythromycin series. Part 13. Synthesis and structure elucidation of 10-dihydro-10-deoxo-11-methyl-11-azaerythromycin A. J. Chem. Res. Synop. 1988 152-153 (1988).

6 Weisblum, B. Erythromycin resistance by ribosome modification. Antimicrob. Agents Chemother. 39, 577-585 (1995).

7 Ajito, K., Miura, T., Furuuchi, T. \& Tamura, A. Sixteen-membered macrolides: chemical modifications and future applications. Heterocycles 89, 281-352 (2014).

8 Shah, P. J., Vakil, N. \& Kabakov, A. Role of intravenous immune globulin in streptococcal toxic shock syndrome and Clostridium difficile infection. Am. J. Health Syst. Pharm. 72, 1013-1019 (2015).

9 Umemura, E. et al. Synthesis of Novel lincomycin derivatives and their in vitro antibacterial activities. J. Antibiot. 66, 195-198 (2013).

10 Wakiyama, Y. et al. Synthesis and structure-activity relationships of novel lincomycin derivatives. Part 1. Newly generated antibacterial activities against Gram-positive bacteria with erm gene by C-7 modification. J. Antibiot. 69, 368-380 (2016).

11 Wakiyama, Y. et al. Synthesis and structure-activity relationships of novel lincomycin derivatives. Part 2. Synthesis of 7(S)-7-deoxy-7-(4-morpholinocarbonylphenylthio)lincomycin and its 3-dimensional analysis with rRNA. J. Antibiot. 69, 428-439 (2016).

12 Kumura, K. et al. Synthesis and antibacterial activity of novel lincomycin derivatives. I. Enhancement of antibacterial activities by introduction of substituted azetidines. J. Antibiot. 69, 440-445 (2016).

13 Denis, A. et al. Synthesis and antibacterial activity of HMR 3647 a new ketolide highly potent against erythromycin-resistant and susceptible pathogens. Bioorg. Med. Chem. Lett. 9, 3075-3080 (1999).

14 Miura, T. et al. Novel azalides derived from sixteen-membered macrolides. I. Isolation of the mobile dialdehyde and its one-pot macrocyclization with an amine. J. Antibiot. 60, 407-435 (2007).

15 Miura, T. et al. Novel azalides derived from 16-membered macrolides. III. Azalides modified at the C-15 and $4^{\prime \prime}$ positions: Improved antibacterial activities. Bioorg. Med. Chem. 18, 2735-2747 (2010).

16 Houtman, R. L. \& Mich, P. Trimethylsilyl ethers of lincomycin and its compounds. US Patent US3418414 (1966). 